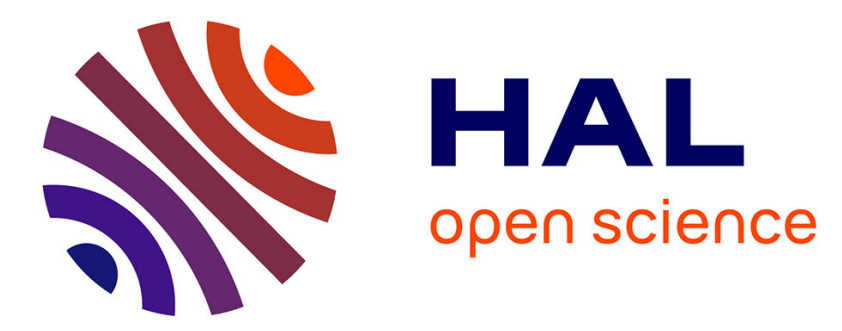

\title{
Definition and use of functional analogues in planetary exploration
}

\author{
F. Foucher, K. Hickman-Lewis, A. Hutzler, K.H. Joy, L. Folco, J.C. Bridges, \\ P. Wozniakiewicz, J. Martínez-Frías, V. Debaille, M. Zolensky, et al.
}

\section{- To cite this version:}

F. Foucher, K. Hickman-Lewis, A. Hutzler, K.H. Joy, L. Folco, et al.. Definition and use of functional analogues in planetary exploration. Planetary and Space Science, 2021, 197, pp.105162. 10.1016/j.pss.2021.105162 . hal-03130725

\section{HAL Id: hal-03130725 \\ https://hal.science/hal-03130725}

Submitted on 22 Nov 2021

HAL is a multi-disciplinary open access archive for the deposit and dissemination of scientific research documents, whether they are published or not. The documents may come from teaching and research institutions in France or abroad, or from public or private research centers.
L'archive ouverte pluridisciplinaire HAL, est destinée au dépôt et à la diffusion de documents scientifiques de niveau recherche, publiés ou non, émanant des établissements d'enseignement et de recherche français ou étrangers, des laboratoires publics ou privés. 


\title{
Definition and use of functional analogues in planetary exploration
}

\author{
F. Foucher ${ }^{\mathrm{a},{ }^{\star}}$, K. Hickman-Lewis ${ }^{\mathrm{a}, \mathrm{b}, \mathrm{s}}$, A. Hutzler ${ }^{\mathrm{c}, \mathrm{d}, \mathrm{q}}$, K.H. Joy ${ }^{\mathrm{e}}$, L. Folco ${ }^{\mathrm{f}, \mathrm{g}}$, J.C. Bridges ${ }^{\mathrm{h}}$, \\ P. Wozniakiewiczi, J. Martínez-Frías ${ }^{j}$, V. Debaillek ${ }^{k}$ M. Zolensky ${ }^{d}$, H. Yano', N. Bost ${ }^{a}$, \\ L. Ferriere ${ }^{m}$, M. Lee ${ }^{n}$, J. Michalski ${ }^{\circ}$, H. Schroeven-Deceuninck ${ }^{p}$, G. Kminek ${ }^{q}$, M. Visor ${ }^{r}$ \\ S. Russells ${ }^{\mathrm{s}, 1}$, C. Smith ${ }^{\mathrm{s}, 2}$, J. Zipfel ${ }^{\mathrm{t}, 3}, \mathrm{~F}$. Westalla, \\ ${ }^{a}$ CNRS, Centre de Biophysique Mol_eculaire, UPR 4301, Rue Charles Sadron, CS80054, 45071, Orl_eans Cedex 2, France

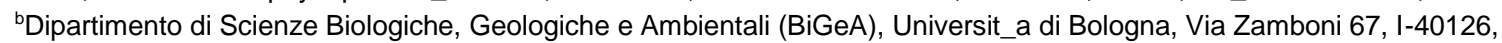 \\ Bologna, Italy \\ 'Lunar and Planetary Institute (USRA), 3600 Bay Area Blvd, Houston, TX, 77058, USA \\ dNational Aeronautics and Space Administration, Lyndon B. Johnson Space Center, 2101 NASA Parkway, Houston, TX, 77058- \\ 3696, USA \\ eDepartment of Earth and Environmental Sciences, University of Manchester, Williamson Building, Oxford Road, Manchester, \\ M13 9PL, UK \\ 'Dipartimento di Scienze Della Terra - Universit_a di Pisa, Via S. Maria 53, 56126, Pisa, Italy \\ ${ }^{9}$ Centro per la Integrazione Della Strumentazione Dell'Universit_a di Pisa (CISUP), Lungarno Pacinotti 43/44, 56126, Pisa, Italy \\ hSpace Research Centre, School of Physics and Astronomy, University of Leicester, LE1 7RH, UK \\ 'School of Physical Sciences, Ingram Building, University of Kent, Canterbury, CT2 7NH, UK \\ 'Instituto de Geociencias (CSIC, UCM), c/ Doctor Severo Ochoa, 7, Edificio Entrepabellones 7 y 8, Ciudad Universitaria, 28040, \\ Madrid, Spain \\ kLaboratoire G-Time, Universit_e Libre de Bruxelles, Avenue F.D. Roosevelt, 50, 1050, Bruxelles, Belgium \\ 'Deptartment of Interdisciplinary Space Science, Institute of Space and Astronautical Science, Japan Aerospace Exploration \\ Agency, 3-1-1 Yoshinodai, Chuo-ku, \\ Sagamihara, Kanagawa, 252-5210, Japan \\ ${ }^{m}$ Naturhistorisches Museum Wien, Burgring 7, 1010, Vienna, Austria \\ nSchool of Geographical \& Earth Sciences, University of Glasgow, Gregory Building, Glasgow, G12 8QQ, UK \\ ${ }^{\circ}$ Department of Earth Sciences, James Lee Building, The University of Hong Kong, Pokfulam Road, Hong Kong \\ ${ }^{P} E S A$ Harwell, Atlas Building, Harwell Oxford, Didcot, Oxfordshire, OX11 OQX, UK \\ "European Space Agency, ESTEC, Keplerlaan 1, 2200, AG, Noordwijk, the Netherlands \\ 'Centre National D'Etudes Spatiales, 2 Place Maurice Quentin, 75039, Paris, Cedex 1, France \\ sDepartment of Earth Sciences, Natural History Museum, Cromwell Road, London, SW7 5BD, United Kingdom \\ 'Senckenberg Gesellschaft für Naturforschung, Senckenberganlage 25, 60325, Frankfurt am Main, Germany \\ * Corresponding author. \\ E-mail address: frederic.foucher@cnrs.fr (F. Foucher). \\ ${ }^{1}$ EURO-CARES Project co-coordinator. \\ ${ }^{2}$ EURO-CARES Project coordinator. \\ ${ }^{3}$ EURO-CARES WP 5 "Analogues" deputy. \\ ${ }^{4}$ EURO-CARES WP 5 "Analogues" leader.
}

\begin{abstract}
The practical limitations inherent to human and robotic planetary exploration necessitate the development of specific protocols and methods. This non-standard approach requires testing and validation phases in order to optimise instrumental setups and improve data interpretation; this can occur prior to, during, or even after a mission. Flight instruments, and/or their spare models, may be evaluated using relevant terrestrial materials and/ or locations. These materials are called analogues: "analogue sites" for large-scale locations, and "analogue samples" for smaller-scale materials. Depending on the scientific domain, the word "analogue" may carry different meanings but is invariably used to denote objects having compositions and/or physical properties similar to specific extraterrestrial objects. However, due to the variability in composition and properties of natural materials, there are always inevitably - some differences between the analogue and the object(s) to which it refers. In analogue studies, it is, thus, important to focus on the specific properties that need to be imitated and to consider analogue properties rather than analogue sites or samples alone. Here, we introduce the concept of "functional analogues". We first make an overview of the different types of analogues and sort them according to their utility. We then describe how different types of functional analogues can be used throughout the timeline of space missions, from the evaluation of different methods in the definition of a
\end{abstract}


mission to understanding the results acquired by probes exploring extraterrestrial bodies. Finally, logical pathways are outlined that facilitate the selection of the best-suited functional analogue(s) according to their intended use and taking into account practical limitations.

Keywords: Analogue, Planetary exploration, Mars, Space missions

\section{Introduction}

Exploration on Earth generally involves a multi-scalar description starting with general geological and environmental context, continuing with outcrop characterisation through drawing maps and sketches and using lenses and sampling using hammers, scoops or coring devices. This process is concluded with laboratory investigations, e.g. using optical microscopy on raw materials, polished sections and/or petrographic thin sections. If required, for specific purposes, different complementary methods are used, such as scanning electron microscopy, Raman and infrared spectroscopy, inductively coupled plasma mass spectrometry and atomic emission spectrometry (ICP-MS and ICP-AES), X-ray diffraction and many others for investigating different scientific questions.

In comparison to analyses carried out on Earth, in situ exploration and analyses in space are more limited for numerous technical reasons. The energy and mass constraints inherent to space probes necessarily imply compromises that lead to decreased resolution, sensitivity and precision; furthermore, some methods are simply incompatible with the specifications of a mission. Analytical protocols are, thus, mission-specific and necessarily follow a different logic from those used on Earth, e.g. on the Moon during the Surveyor missions (Phinney et al., 1969), on Venus during the Venera missions (Surkov et al., 1984), on Titan during the Huygens mission (Lebreton et al., 2005), on Mars during numerous orbiter and rover missions (Klein et al., 1976; Grotzinger et al., 2012; Bost et al., 2015; Mangold et al., 2017; Hickman-Lewis et al., 2020a) or on Mercury during the BepiColombo mission (Schulz and Benkhoff, 2006). The validation of these protocols prior to a mission is crucial to guarantee scientific relevance and to train scientific teams to follow a procedure of investigation that is, for terrestrial scientists, unusual. Ideally, the validation and testing phase must be carried out on samples similar to those that will be analysed during the mission; however, materials from most targeted extraterrestrial bodies are either not available on Earth or sufficiently rare as to be used for instrument testing only in exceptional cases. Therefore, it is necessary to use Earth (terrestrial) materials as analogues.

Depending on the scientific domain, the precise signification of "analogue" may differ but the term is invariably used to denote a terrestrial site, material or object having similar composition and/or properties to a given extraterrestrial site, material or object. Natural materials are, however, variable in composition and exhibit heterogeneity at multiple scales. For instance, most rocks are mineralogically and compositionally varied on macro- and micro-scales such that they fit their designation or nomenclature only when observed at a certain scale (heterogeneous materials such as conglomerates or xenolithic basalts); likewise, most named minerals refer to a range of elemental compositions (solid solution series such as plagioclase feldspar).

Rather than using bulk composition to define and sort analogues, we here choose to base our definition on the use of the site/material/object and its relevance for specific purposes during a mission timeline and thus propose the concept of a functional analogue. Functional analogues are defined as terrestrial sites, materials or objects exhibiting general properties more or less similar to those anticipated on the targeted extraterrestrial body, but having specific analogue properties that are highly or perfectly relevant for a given use. As our knowledge of such bodies deepens, the nature and range of analogues that scientists seek to use is refined and may change. For instance, the samples used in preparation for Mars missions now reflect our better understanding of the geological history of the planet (e.g. Bridges et al., 2015). These different types of functional analogues may have fluctuating relevance depending on the state of development of a mission or on current knowledge of a specific feature; an analogue that is too specific and/or complex may be inappropriate for a given use (e.g. testing the ExoMars drill on a Martian meteorite would be entirely redundant). Therefore, the aim of this study is to define the rationale for the selection of analogues for specific purposes (fundamental science, 
instrumental development, etc.), taking into account practical aspects (amount of sample required, accessibility, cost, etc.) and considering the global timeline of a space mission. This rationalisation of the use of analogues also weighs environmental and financial considerations, such as limiting the use of expensive samples or non-essential travel to exotic terrestrial analogue sites.

A large part of the philosophical approach proposed in this study originates from the fruitful discussions that took place during the first workshops dedicated to analogues organised in the framework of the EURO-CARES (European Curation of Astromaterials Returned from the Exploration of Space) project (Russell et al., 2019; Smith et al., 2021). This project, funded by the Horizon-2020 Framework Programme for Research and Innovation over 2015-2017 period, aimed to create a roadmap for the implementation of a European Extraterrestrial Sample Curation Facility (ESCF) that would be suitable for the curation of samples from all possible return missions likely over the next few decades, i.e. from the Moon, asteroids and Mars. Extraterrestrial samples returned to Earth will require specific storage conditions and handling procedures, in particular for those coming from Mars. For practical reasons and planetary protection concerns, it might be necessary for such a facility to have its own collection of analogue samples permitting the testing of storage conditions and to develop protocols for sample preparation and analyses. Within the framework of the EURO-CARES project, a list of the different types of samples that would be relevant for such a curation facility has been proposed. Nevertheless, these samples are very specific and their selection and definition were addressed during the second part of the EURO-CARES project (Russell et al., 2019; Smith et al., 2021).

\section{Classification of functional analogues}

\subsection{Analogue sites}

Analogue sites are widely employed in support of planetary exploration. They are used to train astronauts, test instruments and/or assist the interpretation of observations made during space missions. Analogue sites can be of differing nature and interest depending on their relevance for a particular necessity or application (Marlow et al., 2008; Preston et al., 2012; Preston and Dartnell, 2014). Compendia of planetary analogue sites can be found in Garry and Bleacher (2011) and Preston et al. (2012).

Herein, we will sort such sites according to their general analogy and distinguish the following categories:

i) Sites used for their planetary analogy;

ii) Sites used for analogies in their mechanical and chemical processes;

iii) Sites used for their petrological and mineralogical analogy;

iv) Analogue sites of astrobiological interest;

v) Engineering analogue sites.

We further sub-sort these different types of analogue sites according to their relevance, their uses and their limits. This description is summarised in Fig. 1.

\subsubsection{Sites used for their planetary analogy}

Relevance: Sites used for their planetary analogy are natural terrestrial locations with large-scale geological structures and geomorphologies similar to those observed or thought to be present on extraterrestrial bodies. Generally, they are produced by planetary dynamic processes and/or events, and, therefore, cannot be representatively reproduced under laboratory conditions. Planetary analogue sites are landscapes or outcrops that may range from a few metres up to several hundred kilometres in size. Their study yields a better understanding of the geological processes involved in the formation of similar structures on extraterrestrial bodies. For example, parameters associated with terrestrial meteorite impact craters permit us to understand their mechanisms of formation, as for the Barringer crater (aka Meteor Crater), Arizona, USA (Melosh and Collins, 2005), or the Ries impact structure in Germany (Arp et al., 2019), thereby helping to interpret the nature and form of impact rocks (impactites) 
found in craters observed on extraterrestrial bodies. Sites used for planetary analogy include a variety of geological landforms and terrains, including impact craters (i.e. simple craters to complex crater structures) desert landforms (e.g. erg, serir, inselbergs, salt lakes and playas), volcanic (e.g. volcanoes, volcanic fields, lava tubes) and hydrothermal (e.g. hot springs, geysers, fumaroles, deep-sea black smokers, mud pots) landforms, and glacial (e.g. glaciers, ice caps, ice fields, subglacial lakes) to periglacial (e.g. eskers, drumlins, pingos, moraines) landforms.
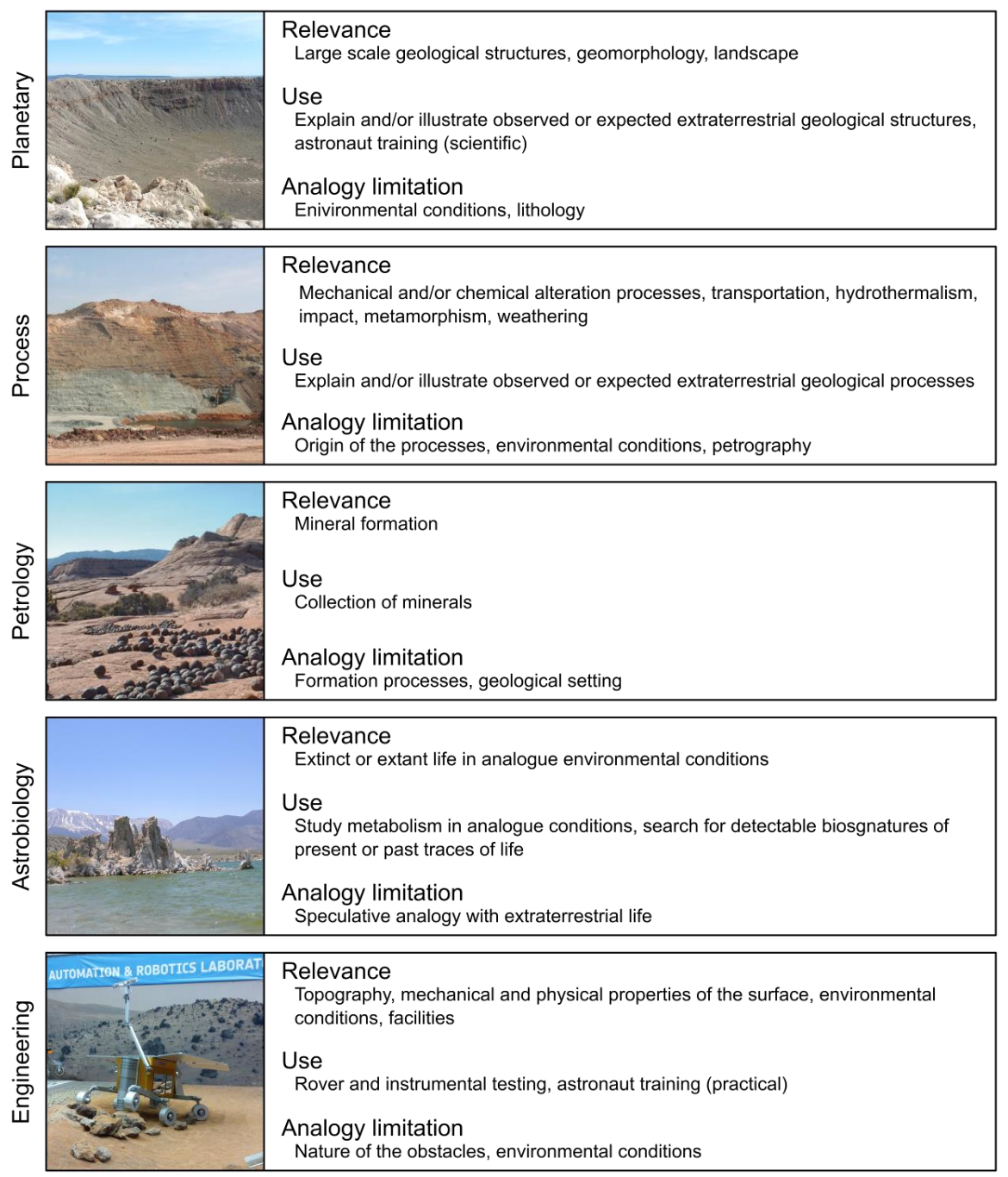

Fig. 1. Different types of analogue sites: relevance, use and limitations. Images from top to bottom: Barringer Crater, Arizona, USA (credit: F. Foucher), Skourriotissa mine, Cyprus (credit: N. Bost), centimetre size haematite blueberries, Utah, USA (credit: M.A. Chan/NASA), Mono Lake, California, SA (credit: F. Foucher), and ESAESTEC, Noordwijk, The Netherlands (credit: F. Foucher).

Uses: Generally, these sites are used for astronaut training or for the elaboration of scientific protocols for investigating extraterrestrial bodies (Mars and the Moon, in particular), taking into account practical limitations inherent to human and robotic exploration. In preparation for the Apollo missions to the Moon, NASA organised many field trips in different analogue sites including volcanic craters, mountains, deserts and impact and explosion craters (Grieve et al., 1988; Lofgren et al., 2011; Lambert et al., 2019). More recently, dedicated training has been organised in the framework of the HI-SEAS (Hawaii Space Exploration Analogue and Simulation) (Häuplik-Meusburger et al., 2017) and the Utah Mars Desert Research Station programmes (Foing et al., 2011). The CanMars analogue mission was organised in 2015-2016 in Utah with the objective of comparing the accuracy of selecting samples remotely using rover data versus a traditional human field exploration in the preparation of future Mars 
sample return missions (Osinski et al., 2019). Tests in caves have also been organised since they are of primary interest for future human exploration (von Ehrenfried, 2019).

Since the majority of these localities have already been extensively described, they can usually be used for scientific comparison based solely on existing literature.

Limitations and precautions: It is important to note that the analogy between these sites and the extraterrestrial locations for which they are analogues remains limited. In particular, rocks on Earth have generally undergone some degree of aqueous or fluvial weathering, metamorphism, oxidation and biological alteration. Most importantly, the diversity of biogeochemical cycling on Earth is uniquely complex in the solar system. Furthermore, the mineralogy may be different, for example, the country rock surrounding meteoritic impact structures is rarely an analogue for similar structures on extraterrestrial bodies. Environmental conditions in terrestrial sites are also usually very different to those encountered during a mission; biological activity, surface temperature, atmospheric composition, pressure and humidity, magnetic fields and gravity are among the many parameters that can play a role in the resulting protocols and in the physical properties of geological structures themselves (e.g. surface alteration, fracturing, etc.). Finally, the formational processes at the origin of the geological structure may also be different. The best example of the latter case is the use of nuclear bomb explosion craters as analogues of impact craters to train astronauts (Lofgren et al., 2011).

\subsubsection{Sites used for analogies in their mechanical and chemical processes}

Relevance: Geodynamic (geophysical) and geochemical processes observed on different solar system bodies include aeolian and aqueous transportation of matter, sedimentation, volcanism, hydrothermalism, tectonics and metamorphism, cryovolcanic and cryosphere effects, weathering and alteration, mass wasting and seismic and other catastrophic processes (e.g. tsunami). The associated analogue sites correspond to where these processes occur either naturally or artificially (i.e. induced by anthropogenic activities) on Earth.

Uses: Such localities may assist the interpretation of local-scale features observed during space missions and may aid in the identification of the mechanical or chemical processes involved.

For mechanical processes, one can cite the terrestrial gullies on Svalbard used as analogues to understand the formation of similar features observed on Mars (Reiss et al., 2011). Other examples include the aeolian segregation of olivine grains observed in Iceland, which has been used to support orbital observations made on Mars (Mangold et al., 2011), and pebble conglomerates observed in the Mojave Desert, USA, which have been used to illustrate the formation of outcrops observed by Curiosity in Gale Crater (Jerolmack, 2013). These analogue sites permit the extrapolation of the mechanical processes involved and enable, for instance, differentiation between aeolian and fluvial transport, thus contributing to palaeoenvironmental reconstructions (Kapui et al., 2018). Recently, lava flows in Hawaii have been used as analogue to better constrain the thicknesses measurement of lava flows observed on the Moon by the Narrow Angle Camera on-board the Lunar Reconnaissance Orbiter (Rumpf et al., 2020).

In terms of chemical processes, the acidic alteration of basaltic rocks in Iceland (Mangold et al., 2012) and in Cyprus (Bost et al., 2012a), as well as the hydrothermal processes occurring at the Dallol geothermal site in the northern Danakil Depression, Ethiopia (Cavalazzi et al., 2019), in Yellowstone National Park, USA (Campbell et al., 2015a), at El Tatio geothermal field in the Chilean Andes (Barbieri and Cavalazzi, 2014), at the Wairakei-Tauhara Taupo volcano in New Zealand (Cattell et al., 2014) or on the Kamchatka Peninsula (Kompanichenko, 2019) are good analogues of early Mars geological processes. Similarly, submarine hydrothermal systems such as the Lost City field are also interesting as analogues of hypothetical hydrothermal systems proposed to exist at the seabed of certain icy moons (Kelley, 2005).

Limitations and precautions: These sites are not necessarily relevant in terms of geological context. Their mineralogies may be different, and the environmental conditions in which they developed are almost certainly different to their extraterrestrial counterparts. For example, the Cyprus locality described in Bost et al. (2012a) is a quarry and its alteration has therefore been induced by anthropogenic activity. 


\subsubsection{Sites used for their petrological and mineralogical analogy}

Relevance: Silicates constitute the most common materials of rocky bodies (along with water ice). Being common on Earth, they therefore constitute the most commonly used analogues. Among others, one can cite extant and extinct volcanic sites: Hawaii, Cinter Cone, La Réunion, Iceland, Etna, Tenerife and the Massif Central. On the contrary, some rocks or minerals observed on extraterrestrial bodies are very uncommon or even do not exist naturally on Earth (e.g. high-pressure water ice). Some are also present in high proportions compared to Earth (e.g. anorthosite on the Moon) and therefore present unique mineralogical scenarios for which few areas on the Earth's surface are representative.

Uses: Sites on Earth where rare materials are exceptionally present are of particular relevance for understanding the extraterrestrial processes leading to their relative abundances, and for adapting or developing protocols and instrumentation. Such examples include the Moqui Marbles from the Navajo Sandstone (southern Utah Desert), which bear similarity to haematite blueberries observed by the Opportunity rover on Mars (Chan et al., 2004). Other examples include sinter deposits in Chile (Ruff and Farmer, 2016) or iron mineral deposits in Rio Tinto (Battler et al., 2012), both of which have been used to explain Mars surface phenomena. The Dallol geothermal site presents several potential opportunities for petrological Martian analogy (Cavalazzi et al., 2019): widespread sulphate- and other salt-bearing deposits throughout their hypersaline pools may be used as analogues for the interpretation of the formation of chloride-bearing salts on Meridiani Planum (Hynek et al., 2015) or possible spring-derived sulphate-bearing deposits throughout Arabia Terra (Franchi et al., 2014; Pondrelli et al., 2015). The Stillwater complex of Montana features anorthosites analogous to lunar basalts (Salpas et al., 1983) and the Vredefort dome in South Africa is also relevant as lunar analogue for metamorphism due to the microstructure of fine-grained granulites observed at this site (Gibson et al., 2002).

Such sites may be relevant for in situ testing of instrumentation or for large-scale exploration of analogue mineralogical environments. Nevertheless, sites of mineralogical and petrological analogy are primarily relevant for the sampling of analogue materials for further laboratory investigations. It is important to note that, depending upon the study, travel to these sites is not necessarily required, since it is possible to obtain samples from numerous existing rock collections (see §2.2).

Limitations and precautions: The analogy of these locations also has limitations, since compositionally similar rocks and minerals may form by various processes in different geological settings; i.e. mineralogical analogue samples can be observed in areas that are not planetary analogue sites. Such analogues may also be greatly restricted in terms of available materials, since many unique minerals occur only in their type localities (this is particularly true for uncommon minerals) and many more in only a few localities at Earth's surface. Finally, even volcanic analogue sites have some limitations and may not necessarily correspond to extraterrestrial volcanics in terms of their mechanical properties (porosity, density, etc.) or detailed composition (e.g. Martian basalts are enriched in iron compared to analogous terrestrial basalts; McSween et al., 2009; Bost et al., 2012b).

\subsubsection{Analogue sites of astrobiological interest}

Relevance: The search for life is one of the key aims of planned future missions to Mars and the icy ocean worlds. The description of biotopes that may be associated with environmental analogues is particularly relevant (Martins et al., 2017; Cabrol, 2018; Cavalazzi et al., 2019). Analogue sites for biological purposes include surface and deep-sea hydrothermal systems (Kelley, 2005; Cousins et al., 2013; Campbell et al., 2015a; b), caves (Boston et al., 2001) and atypical aqueous environments such as Mono Lake in California, USA (Kulp, 2014), Rio Tinto in Spain (Edwards et al., 2007), and Lake Vostok in Antarctica (Shtarkman et al., 2013). A compendium of terrestrial sites of astrobiological relevance for active life can be found in Martins et al. (2017). Other sites are also relevant for palaeobiological studies, for instance fossiliferous Precambrian strata (e.g. Westall et al., 2015; Hickman-Lewis et al., 2020b) or instances where ices or minerals have entrapped and preserved biological remains (e.g. Panieri et al., 2010; Shtarkman et al., 2013). 
Uses: These analogue sites are crucially relevant to train for the detection of biosignatures with limited space instrumentation (Foing et al., 2011; Amador et al., 2015; Vago et al., 2017). For fundamental purposes, studying the range of metabolisms in extremophiles from analogue environments aids our understanding of the adaptation of life to particular conditions. Furthermore, this determines the fundamental requirements (intracellular and extracellular) necessary to live in such environments occurring or potentially occurring on other planetary bodies. These investigations may bring to light the results of convergent evolution in extremophiles, thus defining universal biosignatures such as pigments, biostructures or other geochemical phenomena, that could be used to detect extraterrestrial life. Similarly, ancient fossiliferous sites can be used to determine the nature of fossilised biosignatures and to study their taphonomy, including mineralisation and fossilisation processes, and are thus particularly valuable for data interpretation in astrobiologically oriented missions (Barbieri and Cavalazzi, 2014; Westall et al., 2015; Hickman-Lewis et al., 2020a).

Limitations and precautions: The term analogue may be confusing when applied to biology. Indeed, while basaltic rocks can be considered as analogues since they have been found on various bodies in the solar system, the term analogue is highly speculative for terrestrial microorganisms, since extraterrestrial life has not yet been found. Even if the environmental conditions in these sites are considered very good analogues, this does not necessarily mean that life developed and colonised comparable locations elsewhere in the solar system. Life on Earth probably appeared more than $4 \mathrm{Ga}$ ago and has evolved until the present day, adapting to various environments. This means that life may have appeared in an environment specific to the early Earth prior to colonising modern analogue environments. The presence of life at an analogue site does not necessarily confirm that life may have appeared at such a site (cf. Westall et al., 2015). This is particularly true when considering the present oxygenic conditions on Earth, which are incompatible with prebiotic chemistry and unfavourable to emergence of life. Similarly, since fossilisation processes are dependent both on environmental conditions and on organisms themselves, the use of past traces of life as analogues, including their cellular remains, may also be considered with precaution.

\subsubsection{Engineering analogue sites}

Relevance: Depending on the objective of the test, compositional analogy in the site used may not be a relevant parameter unless it alone reproduces the features of interest. For example, in a rover ground clearance test, the composition of obstacles is not directly relevant, only their height and size. Surfaces with specific mechanical properties (roughness, adhesion, etc.) or cohesion (sand, gravel, etc.) may be also relevant. In order to attain maximum control over the parameters of such tests, they are generally conducted in artificial sites at space agency laboratories. Examples of such testing sites include the 'Mars Yards' at ESA-ESTEC, Noordwijck, Netherlands (https://www.esa.int/esatv/Videos/2018/05/EXOMARS_ready_for_science/Set-up_shots_filmed_in_the _Mars_Yard_ESTEC_Netherlands), at the Jet Propulsion Laboratory, Pasadena (https://wwwrobotics.jpl.nasa.gov/facilities/facility.cfm?Facility $1 / 41$ ) or at Airbus Defence and Space, Stevenage (https://www.airbus.com/space/space-exploration/exomars.html).

Dedicated setups can also be designed to test robotic systems and to validate the architecture of instruments, in particular sensors and controllers and their associated algorithms, using comparable environmental conditions including temperature, pressure, humidity, dust and radiation in simulation chambers, and even gravity in drop towers (e.g. the ZARM Bremen drop tower, https://www.zarm.unibremen.de/en/drop-tower/general-information.html) or during A310-Zero $G$ flight. These sites also include human space flight simulation facilities used to define and test procedures (e.g. swimming pools for astronaut training) and evaluate the psychological effects (claustrophobia, stress, anxiety, loneliness, fear) and physiological strains (food, hygiene, physical activities) associated with space missions. In studies mostly focussed on psychological and practical considerations within the scope of human exploration, geological analogy is irrelevant (the Mars 500 experiment, for example; Ushakov et al., 2014).

On the other hand, it is sometimes useful to make field campaigns in natural sites. This permits the testing of equipment and protocols and training of the scientific team in a more challenging and realistic 
manner than in controlled artificial conditions. This was the objective of the AMASE missions, for instance, where different space instruments and rovers were tested in Svalbard (Léveillé, 2009). NASA's Desert Research and Technology Studies programme carried out tests in Arizona in preparation for future lunar exploration (Abercromby et al., 2012). More recently, the ExoFiT field operations test was organised in the Atacama Desert to train the ExoMars 2022 scientific team (http://www.esa.int/Space_in_Member_States/United_Kingdom/Fit_for_Mars).

Uses: These sites are, by definition, used for robotic vehicle or instrument testing and practical astronaut training. Totally sterile artificial environments could also be useful for planetary protection concerns, particularly to evaluate the dissemination of organic and/or biological materials potentially coming from a space probe or one of its components.

Limitations and precautions: Engineering analogue sites present several limits in terms of analogy. Environmental conditions, such as atmospheric composition, pressure, gravity and radiation are difficult or impossible to mimic in laboratory setups and cannot be reproduced in natural sites. Furthermore, the representativeness of the geological context can be limited. Nevertheless, these sites remain appropriate for their primary purpose, i.e. engineering considerations.

\subsection{Analogue samples}

Similarly to functional analogue sites, we sort functional analogue samples according to their relevance and distinguish the following categories:

i) Geological analogue samples (rocks, minerals and glass);

ii) Chemical samples (molecules);

iii) Samples of biological relevance (living organisms, fossils and biomolecules);

iv) Technical samples (analogues in terms of mechanical, physical and/or chemical properties);

The different types of analogue samples, their relevance, their uses and their limitations are summarised in Fig. 2. 

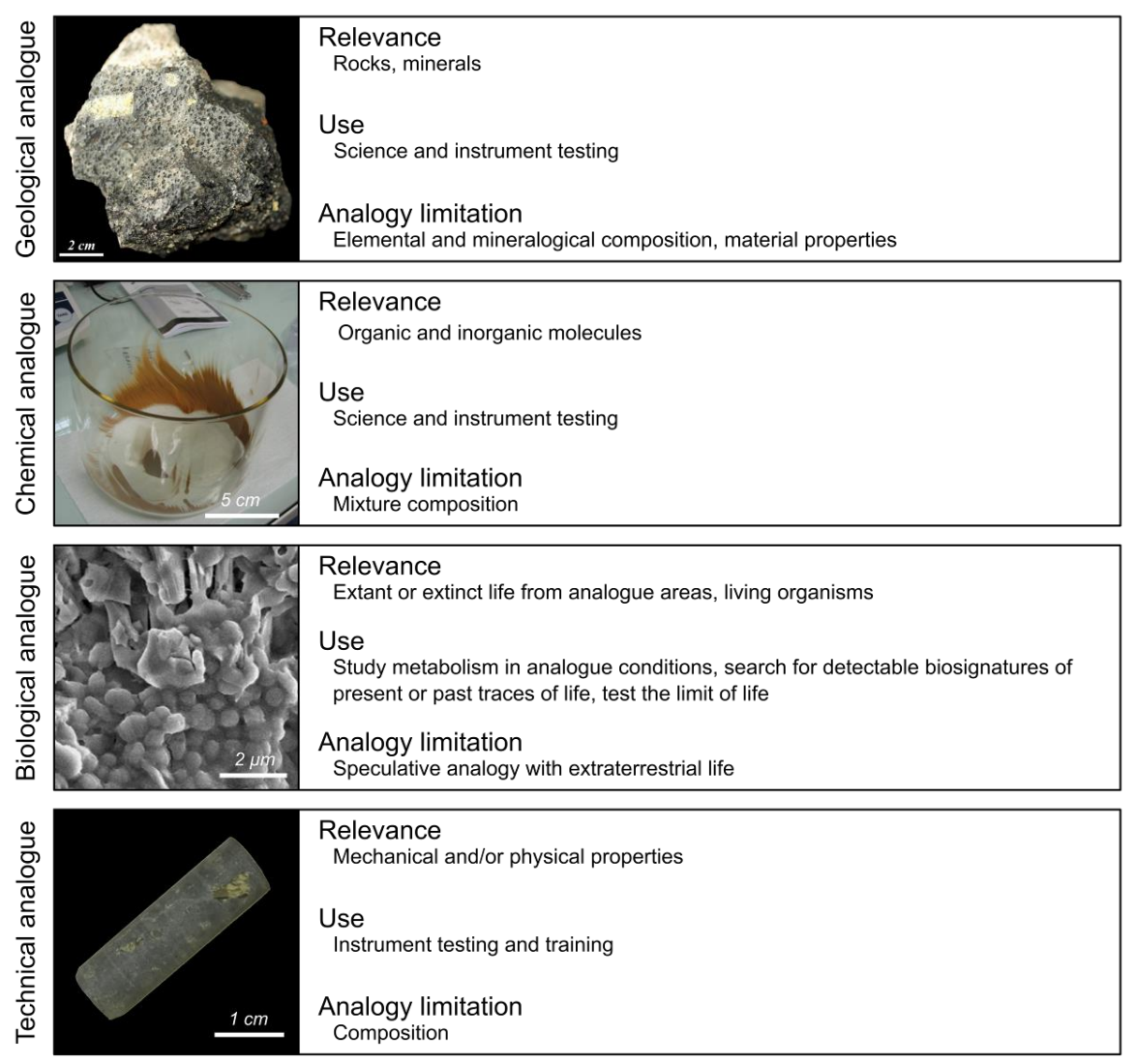

Fig. 2. Classification of analogue samples considering their relevance, use and limitations. Images from top to bottom: Basalt from Svalbard (credit: ISAR), tholin analogues from the PAMPRE experiment, LATMOS, Paris (credit: N. Carrasco, approximate scale bar), 3.446 Ga-old fossilised microbial colonies from the Kitty's Gap chert,

Western Australia (credit: F. Westall), analogue ExoMars 2022 drill core from basanite (credit: F. Foucher).

\subsubsection{Geological analogue samples}

Relevance: Since geological specimens are the main study objectives for most in situ space missions, geological samples are certainly the most obvious analogues and the most broadly useful samples within the framework of space exploration. They are of crucial relevance at all stages of a mission, from fundamental science to engineering development, as discussed later in this paper.

Geological samples can be either natural or artificial.

Uses: Analogue natural minerals can be used in their pure form or in mixtures to test the performance of instruments (IR, Raman, LIBS, XRF,mass spectrometers, etc.) designed to characterise mineral phases (e.g. Edwards et al., 2004; Weider et al., 2011; Bost et al., 2015). Synthetic minerals also provide a means of testing instruments or scenarios on well-characterised intermediate compositions not easily acquired on Earth (based on purity or abundance) but that are likely to be found on other solar system bodies (e.g. Wozniakiewicz et al., 2009; Bost et al., 2012b; Foster et al., 2013).

Similarly, analogue rocks are relevant for testing a wide range of instruments, for training astronauts in geology and to assist in the interpretation of results acquired during missions to the Moon (Morgan et al., 1976; Anbazhagan and Arivazhagan, 2010; Anderson et al., 2015a; Brydges et al., 2015; PernetFisher et al., 2017), Mars (Edwards et al., 1999; Wentworth et al., 2005; Bost et al., 2013, 2015; Cloutis et al., 2015; Manzari et al., 2016; Hickman-Lewis et al., 2020a), Mercury (Jörn et al., 2007) or asteroids (Maturilli et al., 2016). These analogue samples include regolith simulants of Mars (Ramkissoon et al., 2019) and the Moon (Taylor et al., 2016), as well as meteorites (Anderson et al., 2015b, 2020).

Experimentally-heated and irradiated carbonaceous chondrites were of key importance for interpreting the visible/near-infrared spectra of asteroid Ryugu obtained during the Hayabusa2 mission (Nakamura et al., 2019a,b). Furthermore, laboratory impact analogues produced under Stardust encounter conditions have been vital for distinguishing characteristics inherent to Comet Wild 2 samples 
from those produced during their collection (e.g. Ishii et al., 2008; Wozniakiewicz et al., 2012). A similar approach has been used in preparation of the OSIRIS-REx mission (Hanna et al., 2019).

Limitations and precautions: The complexity of geological samples may limit their utility, especially in the case of engineering applications.

Individual minerals may present compositional variations (e.g., solid solution series, chemical zonation) and are thus not necessarily homogeneous in terms of, for example, their major, trace and rare earth element contents. Moreover, depending on their metallogeny, competency and grain size, they may be difficult to extract as pure phases; this is particularly the case for clays that generally occur in association with natural organic components. To circumvent this issue, artificial clays have been synthesised in the laboratory (Decarreau et al., 2008). The geochemistry of natural rocks is very complex and the chemical compositions of two rocks of the same name may vary significantly (e.g. the $\mathrm{SiO}_{2}$ content of basalt ranges from $45 \mathrm{wt} \%$ to $52 \mathrm{wt} \%$ and their alkaline content $\left(\mathrm{Na}_{2} \mathrm{O}+\mathrm{K}_{2} \mathrm{O}\right)$ ranges from $0.1 \mathrm{wt} \%$ to $5 \mathrm{wt} \%)$. Differences in the composition of the source regions and/or the geological processes leading to the formation of mineralogically similar rocks may also differ from one location to another and thus from Earth to elsewhere; e.g. Martian basalts are enriched in iron with respect to most modern terrestrial basalts. Finally, some terrestrial rocks may have been altered or colonised by living organisms. The use of such samples as analogues must be considered carefully, and unwarranted extrapolations must be avoided.

As with minerals, it is possible to synthesise artificial rocks and regolith with controlled compositions (Tosca et al., 2004; Kearsley et al., 2009; Bost et al., 2012b; Cannon et al., 2019); however, it is very difficult to reproduce elemental mixtures and partitioning exactly, especially in large quantities, and rock textures are typically defined by geological processes too complex to mimic in laboratory settings (Taylor et al., 2016). Furthermore, natural samples generally contain most of the elements of the periodic table, ranging from several tens of percent to only a few $\mathrm{ng} / \mathrm{g}$. Even in very low concentrations, elements may play an important role in the crystallisation of minerals, thus reproducing the elemental composition of rocks using only the major elements may alter petrogenetic processes and lead to mineralogical and petrological differences between natural samples and their artificial analogues. Rocks and minerals produced in the laboratory are thus usually intended or the study of one process, or a limited set of variables.

\subsubsection{Chemical analogue samples}

Relevance: In situ space missions often include objectives of organic and inorganic molecule detection in atmospheres, ices, dust or rocks. They are also the principal objects of interest for laboratory and space experiments aiming to study the effects of space, Martian or lunar irradiation on molecules (degradation, racemization and other reactions) directly in space, such as during the EXPOSE experiments (Cottin et al., 2008; Bertrand et al., 2012), or during laboratory simulations (Matthewman et al., 2015, 2016). Chemical analogues are molecules similar to those previously detected during missions and/or those expected based on theoretical models. Since, by definition, a molecule has a given formula (negating purity considerations), most can be purchased from specialised companies. Nevertheless, certain molecules or mixtures, such as insoluble organic matter similar to that detected in meteorites, or tholins observed on Titan, cannot be purchased, but are instead synthesised under analogue conditions using simulation chambers, albeit generally in limited quantities (Brassé et al., 2017; Alcouffe et al., 2010; Biron et al., 2015).

Uses: Chemical analogues are valuable in the testing of space instrumentation. They are also relevant to study the degradation of organics in different extra-terrestrial environments. The synthesis of organic molecules under certain conditions is also used to constrain the variety and proportion of molecules present (Meinert et al., 2012, 2016).

Limitations and precautions: The infinite variety of organic molecules and the inherent heterogeneity of their mixtures at all scales may limit their analogy.

\subsubsection{Biological samples}


Relevance: As stated above, an important aspect of future missions to Mars and other places in the solar system is the search for evidence of past and present extraterrestrial life. The methods used to detect these potential traces of life are necessarily based on terrestrial life, i.e. life as we know it. This implies life based on organic chemistry, thus certain simple biomolecules found in living organisms (such as peptides, lipids or pigments) can be considered as potentially universal or at least relatively common (Baqu_e et al., 2016; Gibard et al., 2018). On the other hand, the remains of primitive microorganisms found in the oldest sediments on Earth can be considered as good analogues for potential extraterrestrial fossilised microbial remains both because they were anaerobic and because certain types were primitive chemotrophs, the kind of microorganisms considered to be possibly the most common in the universe (Westall et al., 2011, 2015). These ancient traces are composed of kerogen resulting from the degradation of biotic organic matter after fossilisation with time and metamorphism. This carbonaceous composition, associated with other elements and minerals and in addition to specific microstructures and morphologies, can be considered as good analogue biosignatures (Foucher and Westall, 2013; Foucher et al., 2015; Westall et al., 2015; Hickman-Lewis et al., 2020b).

Uses: Studies of organisms living in analogous environments or adapting to particular environments simulated in the laboratory may bring to light biosignatures intrinsic to a given environment. Furthermore, when submitted to similar stresses, different forms of life may develop in a similar way. Such convergent evolution or adaptation may lead to convergent biosignatures.

Studying the survival of specific organisms in analogue environments also permits extrapolation to the potential habitability of extraterrestrial bodies and to the study of the limits of life (Rampelotto 2010; Cottin et al., 2017). Microbes are further used as guinea pigs during experiments under space conditions to study the modifications/adaptions of organisms to microgravity, radiation, etc. and to test their survival. These experiments are particularly relevant to evaluate the Panspermia hypothesis (e.g. de la Torre et al., 2010; de Vera et al., 2019), survival during atmospheric entry (de la Torre et al., 2010; Foucher et al., 2010) and survival during meteoritic impact (e.g. Burchell et al., 2004; Ono et al., 2010; Schultz et al., 2014). The study of the survival of microorganisms commonly found in cleanrooms in analogous conditions is very useful to evaluate the risk of contamination of the explored body. Depending of their survival, it is possible to adapt sterilisation procedures in accordance with planetary protection rules. Relevant organisms have also been artificially fossilised in order to study the potential preservation of extraterrestrial microbes (Orange et al., 2009; Gaboyer et al., 2017). Finally, mineralogical samples have been doped with biological compounds to assess the limit of detection of astrobiological instruments (e.g. Vandenabeele et al., 2012; Vitek et al., 2009; Baqu_e et al., 2016). Effective basic and preliminary examination analysis of returned samples (notably from Mars) within a contained environment is a key challenge for sample return (MEPAG, 2012). Extensive use of appropriate analogues is therefore needed to test new and current containment technology (e.g. Holt et al., 2019).

The study of ancient traces of life outlines potentially detectable biosignatures associated with extraterrestrial microfossils, as well as their survival over time, metamorphism, or atmospheric entry (Westall, 2008; Foucher et al., 2010; Campbell et al., 2015b; Westall et al., 2015; Hickman-Lewis et al., 2020b).

Limitations and precautions: As stated before, considering terrestrial life as analogous to extraterrestrial life is highly speculative, despite being necessitated by the fact that it is the sole example of known life in the universe. It may be that extraterrestrial organisms never adapted to the kinds of environments that are Earth-specific or that they used different evolutionary pathways, potentially leading to unexpected biosignatures that we are unable to recognise. For instance, extraterrestrial life is potentially, and even likely, not DNA-based and may use different suites of biomolecules for its metabolism.

\subsubsection{Technical analogue samples}

Relevance: For testing the engineering aspects of techniques, the nature of the sample itself is often irrelevant and the use of geological analogues is often not necessary. For such purposes, it is better to use technical analogue samples which are natural or artificial samples chosen for their physical and/or mechanical properties: size and shape (e.g. drill cores, see Hickman-Lewis et al., 2020a), porosity and 
density (Kearsley et al., 2009), surface roughness, grain size distribution and shape (e.g. sand, silt or clay, see Foucher et al., 2013; Kapui et al., 2018; Just et al., 2020) and other physical properties. Ideally, a technical analogue should not be a natural sample, but rather have perfectly characterised parameters that govern the rationale for its use in testing a specific process or technique. Technical analogues can be made of reference materials known to be specifically adapted to a given technique (e.g. silicon for Raman spectroscopy; Foucher et al., 2013) or particularly representative to test certain parameters of interest (e.g. heating). Unlike other analogues, they can be composed of materials unexpected on the target body.

For instance, tests of dust trapping in the aerogel used in the Stardust mission were conducted using cocoa powder, since it has material properties - including size and density - mimicking those of cometary dust (H€orz et al., 2006). Another example of a technical analogue used for the Stardust mission is the use of mono-disperse spherical glass projectiles to calibrate impactor to impact feature size relations such that a particle flux distribution could be determined for Comet Wild 2 samples, and compared against data from the active detectors on board Stardust as well as data for other solar system objects (Kearsley et al., 2006).

Uses: These samples are typically used for instrumental training and testing. It is important to note that these types of analogues are rarely used for calibration, which is instead conducted using fully characterised calibration samples that are designed or particularly relevant to a given technique (e.g. calibration targets for cameras).

Limitations and precautions: These samples are in general mission specific.

\section{Choosing an appropriate functional analogue}

\subsection{On the use of functional analogues throughout the timeline of a space mission}

Space agencies delineate space missions into different phases, examples of which are displayed in Table 1.

Table 1: The different phases of space missions as defined by (a) ESA and (b) NASA

\begin{tabular}{|c|c|}
\hline Phase 0 & $\begin{array}{c}\text { Mission analysis and } \\
\text { indentification }\end{array}$ \\
\hline Phase A & Feasibility \\
\hline Phase B & Preliminary definition \\
\hline Phase C & Detailed definition \\
\hline Phase D & $\begin{array}{c}\text { Qualification and } \\
\text { production }\end{array}$ \\
\hline Phase E & Utilisation \\
\hline Phase F & Disposal \\
\hline
\end{tabular}

\begin{tabular}{|l|c|}
\hline b $\begin{array}{c}\text { Pre- } \\
\text { Phase A }\end{array}$ & Conceptual study \\
\hline Phase A & Preliminary analysis \\
\hline Phase B & Definition \\
\hline Phase C/D & $\begin{array}{c}\text { Design and } \\
\text { development }\end{array}$ \\
\hline $\begin{array}{c}\text { Operation } \\
\text { Phase }\end{array}$ & $\begin{array}{c}\text { Mission operations } \\
\text { and data analysis }\end{array}$ \\
\hline
\end{tabular}

In the present work, we delineate the timeline of space missions into different phases inspired by these terminologies. This division into specific phases aims to outline the relevance of the different types of analogue described above, from prior to mission design until after the end of the mission. Contrary to their definition in Table 1, certain phases may have unclear boundaries and may overlap temporarily.

\subsubsection{The "conceptual" phase}

This phase corresponds to the bibliographic overview of previous scientific studies concerning the body of interest, including new models and the (re-)interpretation of results obtained during preceding missions. This work is never finished and new findings are continually obtained based on data from 
older missions, for example recent re-interpretations of the data from the Viking probes, some forty years after the missions took place (Levin and Straat, 2016).

During this phase, the most useful analogues are regions characterised by processes that assist understanding of the formation of observed structures or mineralogies; for instance, the variation of olivine in the composition of Martian sand explained by observing Aeolian segregation effects in Icelandic sediments (Mangold et al., 2011). Some geological and chemical analogue samples may also help the interpretation of observations and the validation of hypotheses, for instance laboratorysynthesised tholins used to understand their formation in the atmosphere of Titan (Brassé et al., 2017). Nevertheless, although analogues may be useful for the interpretation of previous mission observations, they are not widely used during this phase.

The result of this phase is the assessment of existing results and the development of hypotheses, together with the listing of crucial missing information required for the validation of these hypotheses. A corollary of this process is that one may begin to define a mission aimed at achieving this objective.

This preliminary phase ranges from phase 0 and the first part of phase $A$ according to ESA definitions and corresponds to NASA pre-phase A (Table 1).

\subsubsection{The "instrumental research and definition" phase}

This second phase involves the selection of payload instrumentation, putting into perspective the data and methodologies that are required to reach the mission objectives defined in the "conceptual" phase. Despite ongoing technological advances, instrumental techniques used in space exploration are generally limited with respect to laboratory instrumentation for reasons of cost, size and energy. Certain methods are also incompatible with space exploration. The design of innovative new methods and instruments that could circumvent these limitations is made at this stage. A wide variety of analogues is used for multiple critical purposes during this phase. Indeed, they allow instrumental developers and scientists to test and demonstrate the engineering and scientific potentials of new technologies, instruments and protocols:

- sites relevant for their planetary analogy could be used to prepare for human missions;

- sites relevant for their processes and biological analogy can be used to test instruments in the field, to understand the effects of environmental characteristics on instrumental operation and protocols, or to collect biological samples and test methods of life detection;

- geological and mineralogical analogue samples can be collected for use in future instrumental development (e.g. for calibration) and demonstration; and

- specific instruments can be tested using chemical analogues under laboratory conditions.

These tests and studies are of particular importance since, if progress leading to the improvement of unsatisfactory results is not possible, the mission may be postponed, instruments may be de-scoped or the expected scientific return of the mission may need to be revised.

The "instrumental research and definition" phase is purely concerned with the selection of relevant methods, and not the construction of instruments, which occurs in the next phase. This phase ranges from phase $A$ to phase $C$ according to ESA definitions and from the end of pre-phase $A$ to the beginning of phase C/D according to the NASA definitions (Table 1).

\subsubsection{The "mission design and development" phase}

Once the scientific objectives have been fixed, the global design of the mission has been outlined and the payload instrumentation has been selected, the crucial phase of the design and optimisation of flight instruments and their associated models begins (Engineering Model (EM), Qualification Model (QM), Flight Model (FM), Flight Spare (FS), Flight Representative Test Model (FRTM)). This timeconstrained phase is mainly focussed on the technological and practical aspects of the mission. It is also the period during which landing site selection is undertaken (if the mission involves rovers and/or landers). 
Most analogues are not useful during this phase, the demonstration of the methods having been conducted during the previous phase. The testing and optimisation of systems is achieved using calibration samples. Calibration samples are fully characterised materials that are particularly adapted for, or relevant to, a given technique and are not necessarily analogous to the target body (e.g. calibration targets for cameras). Only engineering analogue sites and technical analogue samples are used during this phase in order to validate technical aspects, such as the mobility of a rover, or access to sample holders.

We strongly suggest that other types of analogue samples and sites of process and/or biological analogy should be used at the end of this phase to verify and demonstrate the ability of the mission to attain its objectives and, if necessary, to adjust instrumental setups and protocols in order to optimise scientific return (Bost et al., 2015; Hickman-Lewis et al., 2020a). Nevertheless, these tests are rarely done prior to the launch due to a shortage of time after the delivery of the instrument flight models. Such tests are instead usually made after the launch using flight spare instruments, whilst the probe travels from Earth to the target body (e.g. for the Rosetta mission, Le Roy et al., 2012).

This phase ranges from the end of phase $B$ to the end of phase $D$ according to ESA definitions and corresponds to phases B and C/D according to the NASA definitions (Table 1).

\subsubsection{The "mission" phase}

This phase corresponds to in situ operations conducted on the target body. The aim is to maximise the scientific return of the on-board instrumentation and to adapt protocols where necessary in the course of discoveries and unexpected events.

Engineering analogue sites may be useful during this phase to test several possibilities prior to choosing the optimal solution to mitigate challenges. An example of the use of such an analogue was the reproduction of the Spirit rover configuration when the rover was stuck in soft regolith on Mars in order to test solutions for extricating itself (https://www.nasa.gov/mission pages/mer/images/mer20090914.html).

From a scientific point of view, however, geological and chemical analogue samples may also be necessary to improve interpretations to be made in situ (e.g. ChemCam on MSL; Clegg et al., 2017).

This phase corresponds to phase E according to ESA definitions and to the mission operations phase according to NASA definitions (Table 1).

\subsubsection{The "results" phase}

The results phase corresponds both to the description of measurements made during the mission as well as their interpretation, which could continue indefinitely, as in the case of the discussion of Viking data. This phase essentially comprises the scientific return of the mission and aims to report, explain and discuss the measurements obtained with the on-board instrumentation. For this scientific phase, geological and chemical analogue samples are used together with sites of geomorphological and petrological analogy as comparison material to enable the interpretation of datasets coming from one or several instruments. This ultimately validates or invalidates hypotheses (e.g. pebbles from Mojave Desert used to interpret Curiosity observations, as mentioned above).

This phase ranges from the end of phase $E$ to the end of phase $F$ according to ESA definitions and corresponds to the data analysis phase according to NASA definitions (Table 1).

\subsubsection{The "summary and perspective" phase}

This last phase corresponds to analyses and interpretations conducted post-mission in addition to results coming from other missions. It consists of the long-term scientific interpretation of the results taking into account new discoveries, reprocessing of data using new methods, and the implications and perspectives arising from these interpretation for future missions. The principal aim of this stage is very different to that of the "results" phase; here, measurements are used for the discussion of scientific hypotheses and are interpreted in a wider context together with results from other sources. This phase 
is undertaken both by the mission team and by other teams who may be undertaking similar missions. It is thus also the "conceptual" phase of future missions (see §2.1.1).

This phase ranges from phase 0 to the first part of phase $A$ according to ESA definitions and corresponds to NASA pre-phase A of a new mission (Table 1).

These phases and their associated relevant analogues are outlined in Fig. 3.

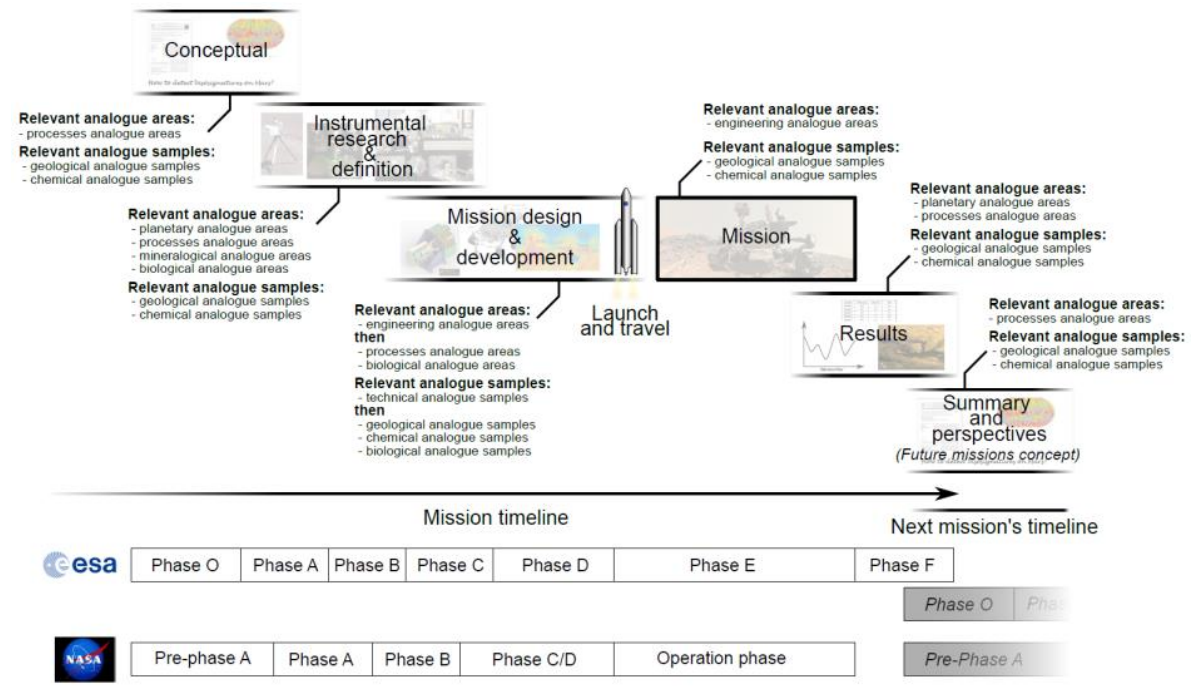

Fig. 3. Schematic global timeline of a space mission and associated relevant analogue sites and samples.

\subsection{How to choose the appropriate analogue}

By definition, the perfect analogue that matches or mimics all properties of an extra-terrestrial site or sample does not exist. The originality of the approach proposed above is to define analogues not from their bulk physical or chemical properties but from the properties that make them appropriate for their specific use. This increases the range of possible analogues while warranting their relevance to the process or observation to which they refer. Indeed, most testing can be conducted with partially analogous samples and only the final testing of instrumentation or attempts at detailed reconstruction of observations should necessitate a highly analogous sample. Using this approach, any sample can be considered an analogue for a specific objective from one or more of its properties or features. Thus, it is not necessary to take overcomplicated, expensive or rare samples as ideal analogues when their properties and functions can be found with more reasonable alternatives (e.g. the use of Icelandic tholeiite to prove that a spectrometer can detect olivine is not necessarily justifiable or relevant when any sample containing olivine could serve the same purpose).

Nevertheless, it may appear difficult to choose the best-suited analogue for a particular purpose; it is necessary to take into account practical considerations such as time, money, facilities and analogue availability (e.g. location and abundance). Thus, we propose a logical pathway scheme that can be used to choose the most appropriate type of analogue to use (whether site and/or sample) depending on the purpose of the test or experiments to be carried out (Fig. 4).

Fig. 4. (Next Page) Logical pathways justifying the choice of the most appropriate type of analogue sites and/or samples to use depending on the purpose of the study. 


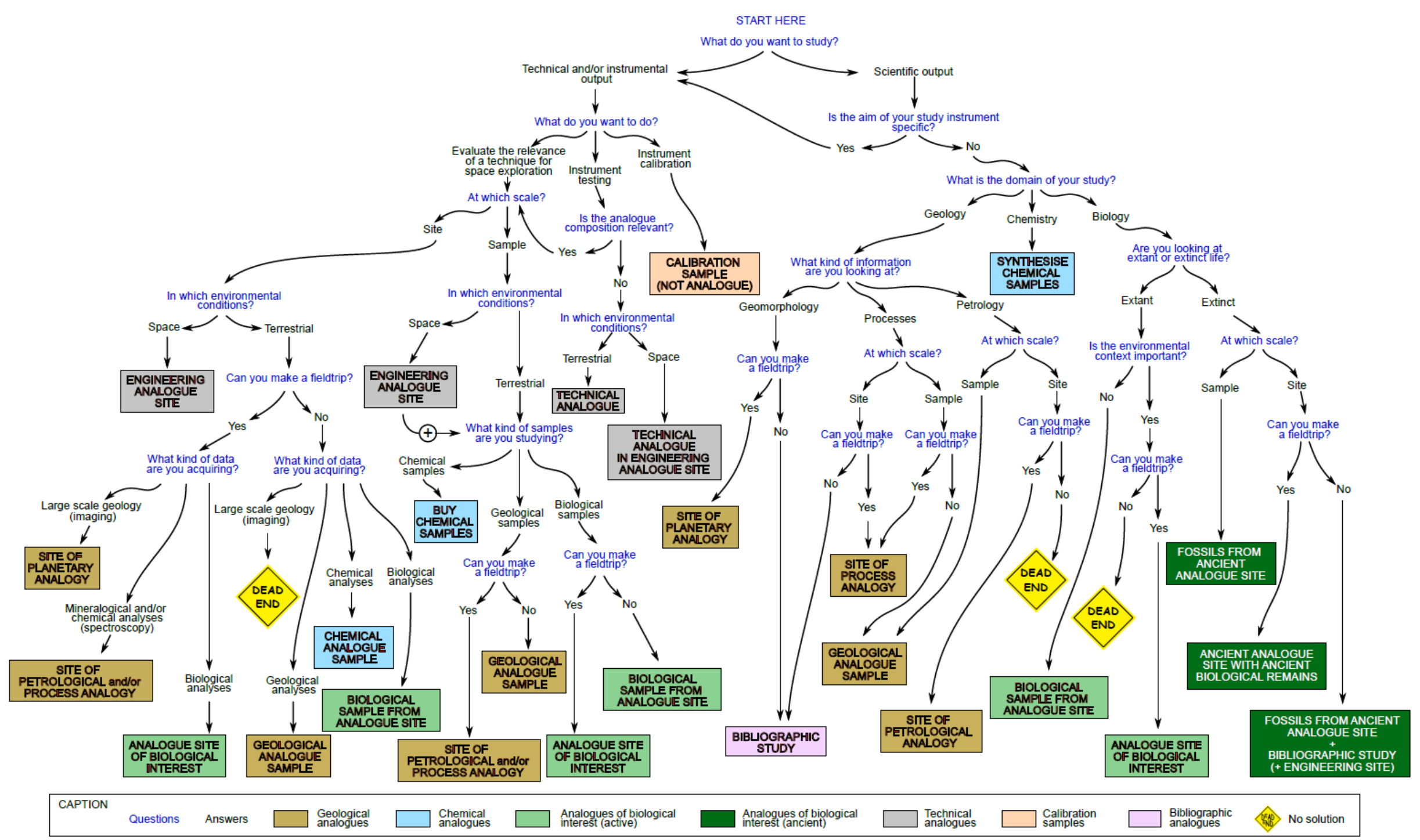




\section{Conclusion}

A review of planetary science literature shows that behind the word "analogue" is hidden a huge variety of objects and ideas depending upon both the scientific domain and the background of scientists, even if all such studies refer to the broad concept of terrestrial objects with similar properties to extraterrestrial objects. Therefore, we have introduced the concept of a "functional analogue", for which the analogy is defined according to its use. The rationale for using a particular functional analogue was discussed and a scheme showing logical pathways was proposed to aid in the selection of the bestsuited analogue for use according to the objectives of study while taking into account practical limitations. Such an approach is useful in the preparation of future planetary missions and potentially crucial for interpreting data obtained during the mission.

\section{Acknowledgments}

We thank the HORIZON-2020 Framework Programme for Research and Innovation for funding of EURO-CARES project (grant agreement ID: 640190) and all the EURO-CARES consortium since a large part of the philosophical framework of this study resulted from a number of fruitful discussions, in particular during workshops dedicated to the use of analogue samples in a curation facility. We thank CNES for funding.

\section{References}

Abercromby, A.F.J., Gernhardt, M.L., Litaker, M.L., 2012. Desert Research and technology studies (DRATS) 2009: a 14-day evaluation of the space exploration vehicle prototype. In: A Lunar Analog Environment, NASA/TP-2012-217360, p. 144.

Alcouffe, G., Cavarroc, M., Cernogora, G., Ouni, F., Jolly, A., Boufendi, L., Szopa, C., 2010. Capacitively coupled plasma used to simulate Titan's atmospheric chemistry. Plasma Sources Sci. Technol. 19, 11.

Amador, E.S., Cable, M.L., Chaudry, N., Cullen, T., Gentry, D., Jacobsen, M.B., Murukesan, G., Schwieterman, E.W., Stevens, A.H., Stockton, A., Yin, C., Cullen, D.C., Geppert, W., 2015. Synchronous in-field application of life-detection techniques in planetary analog missions. Planet. Space Sci. 106, 1-10.

Anbazhagan, S., Arivazhagan, S., 2010. Reflectance spectra of analog anorthosites: implications for lunar highland mapping. Planet. Space Sci. 58 (5), 752-760.

Anderson, F.S., Levine, J., Whitaker, T.J., 2015a. Rb-Sr resonance ionization geochronology of the Duluth Gabbro: a proof of concept for in situ dating on the Moon. Rapid Commun. Mass Spectrom. 29 (16), 1457-1464.

Anderson, F.S., Levine, J., Whitaker, T.J., 2015b. Dating the Martian meteorite Zagami by the 87Rb-87Sr isochron method with a prototype in situ resonance ionization mass spectrometer. Rapid Commun. Mass Spectrom. 29 (2), 191-204.

Anderson, F.S., Levine, J., Whitaker, T.J., 2020. Dating a Martian meteorite with 20 Myr precision using a prototype in-situ dating instrument. Planet. Space Sci. 105007.

Arp, G., Schultz, S., Karius, V., Head III, J.W., 2019. Ries impact crater sedimentary conglomerates: sedimentary particle 'impact pre-processing', transport distances and provenance, and implications for Gale crater conglomerates, Mars. Icarus 321 , 531-549.

Baqué, M., Verseux, C., Bottger, U., Rabbow, E., de Vera, J.-P.P., Billi, D., 2016. Preservation of biomarkers from cyanobacteria mixed with Mars like regolith under simulated martian atmosphere and UV flux. Orig. Life Evol. Biosph. 46, 289310.

Barbieri, R., Cavalazzi, B., 2014. How do modern extreme hydrothermal environments inform the identification of martian habitability? The Case of the El Tatio Geyser Field. Challenges 5, 430-443.

Battler, M.M., Osinski, G.R., Lim, D.S.S., Davila, A.F., Michel, F.A., Craig, M.A., Izawa, M.R.M., Leoni, L., Slater, G.F., Fairen, A.G., Preston, L.J., Banerjee, N.R., 2012. Characterization of the acidic cold seep emplaced jarositic Golden Deposit, NWT, Canada, as an analogue for jarosite deposition on Mars. Icarus 224, 382-398. 
Bertrand, M., Chabin, A., Brack, A., Cottin, H., Chaput, D., Westall, F., 2012. The PROCESS experiment: exposure of amino acids in the EXPOSE-E experiment on the international space station and in laboratory simulations. Astrobiology 12 (5), $426-435$.

Biron, K., Derenne, S., Robert, F., Rouzaud, J.-N., 2015. Toward an experimental synthesis of the chondritic insoluble organic matter. Meteoritics Planet Sci. 50, 1408-1422.

Bost, N., Westall, F., Ramboz, C., Fontaine, C., Meunier, A., Foucher, F., 2012a. Hydrothermal, Deuteric and Acidic Basalt Alteration at the Skouriotissa Mine, Cyprus: Relevance for Mars. EGU General Assembly, Vienna, Austria. April 23-27, abstract 1407.

Bost, N., Westall, F., Gaillard, F., Ramboz, C., Foucher, F., 2012b. Synthesis of a spinifex textured basalt as an analog to Gusev crater basalts, Mars. Meteoritics Planet Sci. 47, 820-831.

Bost, N., Westall, F., Ramboz, C., Foucher, F., Pullan, D., Meunier, A., Petit, S., Fleischer, I., Klingelhofer, G., Vago, J., 2013. Missions to Mars: characterisation of Mars analogue rocks for the international space analogue rockstore (ISAR). Planet. Space Sci. 82-83, 113-127.

Bost, N., Ramboz, C., Breton, N.L., Foucher, F., Lopez-Reyes, G., Angelis, S.D., Josset, M.,Venegas, G., Sanz-Arranz, A., Perez, F.R., Medina, J., Josset, J.-L., Souchon, A., Ammannito, E., Carli, C., Vago, J.L., Westall, F., 2015. Testing the ability of the ExoMars 2018 payload to document geological context and potential habitability on Mars. Planet. Space Sci. 108, 87-97.

Boston, P.J., Spilde, M.N., Northup, D.E., Melim, L.A., Soroka, D.S., Kleina, L.G., Lavoie, K.H., Hose, L.D., Mallory, L.M., Dahm, C.N., Crossey, L.J., 2001. Cave biosignature suites: microbes, minerals, and Mars. Astrobiology 1 (1), 25-55.

Brasse, C., Buch, A., Coll, P., Raulin, F., 2017. Low-temperature alkaline pH hydrolysis of oxygen-free titan tholins: carbonates' impact. Astrobiology 17 (1), 8-26.

Bridges, J.C., Schwenzer, S.P., Leveille, R., Westall, F., Wiens, R.C., Mangold, N., Bristow, T., Edwards, P., Berger, G., 2015. Diagenesis and clay mineral formation at Gale Crater, Mars. J. Geophys. Res.: Plan 120 (1), 1-19.

Brydges, T.F.V., Marriner, C.M., Donaldson Hanna, K.L., Bowles, N.E., MacDonald, R., 2015. Characterisation of miyakejima anorthite as a lunar analogue. Lunar and Planetary Science Conference 46, 1251.

Burchell, M.J., Mann, J.R., Bunch, A.W., 2004. Survival of bacteria and spores under extreme shock pressures. Mon. Not. Roy. Astron. Soc. 352, 1273-1278.

Cabrol, N.A., 2018. The coevolution of life and environment on Mars: an ecosystem perspective on the robotic exploration of biosignatures. Astrobiology 18 (1), 1-27.

Campbell, K.A., Guido, D.M., Gautret, P., Foucher, F., Ramboz, C., Westall, F., 2015a.Geyserite in hot-spring siliceous sinter: window on Earth's hottest terrestrial (paleo) environment and its extreme life. Earth Sci. Rev. 148, 44-64.

Campbell, K.A., Lynne, B.Y., Handley, K.M., Jordan, S., Farmer, J.D., Guido, D.M., Foucher, F., Turner, S., Perry, R.S., $2015 b$. Tracing biosignature preservation of geothermally silicified microbial textures into the geological record. Astrobiology 15 (10), 858-882.

Cannon, K.M., Britt, D.T., Smith, T.M., Fritsche, R.F., Batcheldor, D., 2019. Mars global simulant MGS-1: a Rocknest-based open standard for basaltic martian regolith simulants. Icarus 317, 470-478.

Cattell, H., Cole, J., Oze, C., Allen, S., 2014. Eruptive origins of a lacustrine pyroclastic succession: insights from the middle huka falls formation, Taupo volcanic zone, New Zealand. N. Z. J. Geol. Geophys. 57, 331-343.

Cavalazzi, B., Barbieri, R., Gomez, F., Capaccioni, B., Olsson-Francis, K., Pondrelli, M.,Rossi, A., Hickman-Lewis, K., Agangi, A., Gasparotto, G., Glamoclija, M., Ori, G., Rodriguez, N., Hagos, M., 2019. The Dallol geothermal site, northern Afar (Ethiopia) an exceptional planetary field analog on earth. Astrobiology 19 (4), 553-578.

Chan, M.A., Beitler, B., Parry, W.T., Ormo, J., Komatsu, G., 2004. A possible terrestrial analogue for haematite concretions on Mars. Nature 429, 731-734.

Clegg, S., Wiens, R.C., Anderson, R., Forni, O., Frydenvang, J., Lasue, J., Cousin, A.,Payre, V., Boucher, T., Dyar, M., McLennan, S., Morris, R.V., Graff, T., Mertzman, S., Ehlmann, B., Belgacem, I., Newsom, H., Clark, B., Melikechi, N., Mezzacappa, A., Mclnroy, R., Martinez, R., Gasda, P., Gasnault, O., Maurice, S., 2017. Recalibration of the Mars science laboratory ChemCam instrument with an expanded geochemical database. Spectrochim. Acta, Part B 129, 64-85.

Cloutis, E.A., Mann, P., Izawa, M.R.M., Applin, D.M., Samson, C., Kruzelecky, R., Glotch, T.D., Mertzman, S.A., Mertzman, K.R., Haltigin, T.W., Fry, C., 2015. The Canadian space agency planetary analogue materials suite. Planet. Space Sci. 119, 155172.

Cottin, H., Coll, P., Coscia, D., Fray, N., Guan, Y.Y., Macari, F., Raulin, F., Rivron, C., Stalport, F., Szopa, C., Chaput, D., Viso, M., Bertrand, M., Chabin, A., Thirkell, L., Westall, F., Brack, A., 2008. Heterogeneous solid/gas chemistry of organic 
compounds related to comets, meteorites, Titan, and Mars: laboratory and in lower Earth orbit experiments. Adv. Space Res. 42 , 2019-2035.

Cottin, H., Kotler, J.M., Bartik, K., Cleaves, H.J., Cockell, C.S., de Vera, J.-P.P., Ehrenfreund, P., Leuko, S., Kate, I.L.T., Martins, Z., Pascal, R., Quinn, R., Rettberg, P., Westall, F., 2017. Astrobiology and the possibility of life on earth and elsewhere. Space Sci. Rev. 209, 1-42.

Cousins, C.R., Crawford, I., Carrivick, J., Gunn, M., Harris, J., Kee, T., Karlsson, M.,Carmody, L., Cockell, C., Herschy, B., Joy, K., 2013. Mars analogue glaciovolcanic hydrothermal environments in Iceland: detection and implications for astrobiology. J. Volcanol. Geoth. Res. 256, 61-77.

Decarreau, A., Petit, S., Martin, F., Farges, F., Vieillard, P., Joussein, E., 2008.Hydrothermal synthesis, between 75 and 150C, of high-charge, ferric nontronites. Clay Clay Miner. 56 (3), 322-337.

de la Torre, R., Sancho, L.G., Horneck, G., de los Ríos, A., Wierzchos, J., Olsson-Francis, K., Cockell, C.S., Rettberg, P., Berger, T., de Vera, J.-P.P., Ott, S., Martinez-Frías, J., Melendi, P.G., Lucas, M.M., Reina, M., Pintado, A., Demets, R., 2010. Survival of lichens and bacteria exposed to outer space conditions - results of the Lithopanspermia experiments. Icarus 208, 735748.

de Vera, J.-P., Alawi, M., Backhaus, T., Baque, M., Billi, D., Bottger, U., Berger, T., Bohmeier, M., Cockell, C., Demets, R., de la Torre Noetzel, R., Edwards, H., Elsaesser, A., Fagliarone, C., Fiedler, A., Foing, B., Foucher, F., Fritz, J., Hanke, F., Herzog, T., Horneck, G., Hübers, H.-W., Huwe, B., Joshi, J., Kozyrovska, N., Kruchten, M., Lasch, P., Lee, N., Leuko, S., Leya, T., Lorek, A., Martinez-Frias, J., Meessen, J., Moritz, S., Moeller, R., Olsson-Francis, K., Onofri, S., Ott, S., Pacelli, C., Podolich, O., Rabbow, E., Reitz, G., Rettberg, P., Reva, O., Rothschild, L., Sancho, L.G., Schulze-Makuch, D., Selbmann, L., Serrano, P., Szewzyk, U., Verseux, C., Wadsworth, J., Wagner, D., Westall, F., Wolter, D., Zucconi, L., 2019. Limits of life and the habitability of Mars: the ESA space experiment BIOMEX on the ISS. Astrobiology 19 (2), 145-157.

Edwards, H.G.M., Farwell, D.W., Grady, M.M., Wynn-Williams, D.D., Wright, I.P., 1999. Comparative Raman microscopy of a Martian meteorite and Antarctic lithic analogues. Planet. Space Sci. 47 (3-4), 353-362.

Edwards, H.G.M., Jorge-Villar, S.E., Bishop, J.L., Bloomfield, M., 2004. Raman spectroscopy of sediments from the Antarctic Dry Valleys, an analogue study for exploration of potential paleolakes on Mars. J. Raman Spectrosc. 35, 458-462.

Edwards, H.G.M., Vandenabeele, P., Jorge-Villar, S.E., Carter, E.A., Perez, F.R., Hargreaves, M.D., 2007. The Rio Tinto Mars Analogue site: an extremophilic Raman spectroscopic study. Spectrochim. Acta, Part A 68, 1133-1137.

Foing, B.H., Stoker, C., Ehrenfreund, P., 2011. Astrobiology field research in Moon/Mars analogue environments: Preface. Int. J. Astrobiol. 10, 137-139.

Foster, N.F., Wozniakiewicz, P.J., Price, M.C., Kearsley, A.T., Burchell, M.J., 2013. Identification by Raman spectroscopy of Mg-Fe content of olivine samples after impact at $6 \mathrm{~km} \mathrm{~s}-1$ onto aluminium foil and aerogel, in the laboratory and in Wild-2 cometary samples. Geochem. Cosmochim. Acta 121, 1-14.

Foucher, F., Westall, F., Brandstatter, F., Demets, R., Parnell, J., Cockell, C.S., Edwards, H.G.M., Beny, J.-M., Brack, A., 2010. Testing the survival of microfossils in artificial martian sedimentary meteorites during entry into Earth's atmosphere: the STONE 6 experiment. Icarus 207, 616-630.

Foucher, F., Westall, F., 2013. Raman imaging of metastable opal in carbonaceous microfossils of the 700-800 Ma old Draken Formation. Astrobiology 13 (1), 57-67.

Foucher, F., Lopez-Reyes, G., Bost, N., Perez, F.R., Russmann, P., Westall, F., 2013. Effect of grain size distribution on Raman analyses and the consequences for in situ planetary missions. J. Raman Spectrosc. 44, 916-925.

Foucher, F., Ammar, M.-R., Westall, F., 2015. Revealing the biotic origin of silicified Precambrian carbonaceous microstructures using Raman spectroscopic mapping, a potential method for the detection of microfossils on Mars. J. Raman Spectrosc. 46, 873-879.

Franchi, F., Rossi, A.P., Pondrelli, M., Cavalazzi, B., 2014. Geometry, stratigraphy and evidences for fluid expulsion within Crommelin crater deposits, Arabia Terra, Mars. Planet. Space Sci. 92, 34-48.

Gaboyer, F., Milbeau, C.L., Bohmeier, M., Schwendner, P., Vannier, P., Beblo-Vranesevic, K., Rabbow, E., Foucher, F., Gautret, P., Guegan, R., Richard, A., Sauldubois, A., Richmann, P., Perras, A.K., Moissl-Eichinger, C., Cockell, C.S., Rettberg, P., Marteinsson, V., Monaghan, E., Ehrenfreund, P., Garcia-Descalzo, L., Gomez, F., Malki, M., Amils, R., Cabezas, P., Walter, N., Westall, F., 2017. Mineralization and preservation of an extremotolerant bacterium isolated from an early Mars analog environment. Sci. Rep. 7, 8775. Boulder.

Garry, W.B., Bleacher, J.E., 2011. Analogs for Planetary Exploration, Special Paper 483. The Geological Society of America, 
Gibard, C., Bhowmik, S., Karki, M., Kim, E.-K., Krishnamurthy, R., 2018. Phosphorylation, oligomerization and self-assembly in water under potential prebiotic conditions. Nat. Chem. 10, 212-217.

Gibson, R.L., Reimold, W.U., Ashley, A.J., Koeberl, C., 2002. Metamorphism on the Moon: a terrestrial analogue in the Vredefort dome, South Africa? Geology 30 (5), 475-478.

Grieve, R.A.F., Wood, C.A., Garvin, J.B., McLaughlin, G., McHone Jr., J.F., 1988. Astronaut's Guide to Terrestrial Impact Craters. LPI Technical Report, 88-03.

Grotzinger, J.P., Crisp, J., Vasavada, A.R., Anderson, R.C., Baker, C.J., Barry, R., Blake, D.F., Conrad, P., Edgett, K.S., Ferdowski, B., Gellert, R., Gilbert, J.B., Golombek, M., Gomez-Elvira, J., Hassler, D.M., Jandura, L., Litvak, M., Mahaffy, P., Maki, J., Meyer, M., Malin, M.C., Mitrofanov, I., Simmonds, J.J., Vaniman, D., Welch, R.V., Wiens, R.C., 2012. Mars science laboratory mission and science investigation. Space Sci. Rev. 170, 5-56.

Hanna, K.D., Schrader, D.L., Cloutis, E.A., Cody, G.D., King, A.J., McCoy, T.J., Applin, D.M., Mann, J.P., Bowles, N.E., Brucato, J.R., Connolly Jr., H.C., 2019. Spectral characterization of analog samples in anticipation of OSIRIS-REx's arrival at Bennu: a blind test study. Icarus 319, 701-723.

Hauplik-Meusburger, S., Binsted, K., Bassingthwaighte, T., Petrov, G., 2017. Habitability Studies and Full Scale Simulation Research: Preliminary Themes Following HISEAS Mission IV, 47th International Conference on Environmental Systems, ICES2017-138, 16-20 July 2017. Charleston, South Carolina, pp. 1-17 abstract 138.

Hickman-Lewis, K., Foucher, F., Pelletier, S., Messori, F., Westall, F., 2020a. Geological appraisals of core samples using the ExoMars 2020 rover instrumentation. Planet. Space Sci. 180, 104743.

Hickman-Lewis, K., Cavalazzi, B., Sorieul, S., Gautret, P., Foucher, F., Whitehouse, M.J., Jeon, H., Georgelin, T., Cockell, C.S., Westall, F., 2020b. Metallomics in deep time and the influence of ocean chemistry on the metabolic landscapes of Earth's earliest ecosystems. Sci. Rep. 10, 4965.

Holt, J.M.C., Bridges, J.C., Vrublevskis, J., Gaubert, F., 2019. Double Walled Isolator Technology for Mars Sample Return Facilities. LPSC abstract 2408.

Horz, F., Bastien, R., Borg, J., Bradley, J.P., Bridges, J., Brownlee, D., Burchell, M., Chi, M., Cintala, M., Dai, Z., Djouadi, Z., Dominguez, G., Economou, T., Fairey, S., Floss, C., Franchi, I., Graham, G., Green, S., Heck, P., Hoppe, P., Huth, J., Ishii, H., Kearsley, A., Kissel, J., Leitner, J., Leroux, H., Marhas, K., Messenger, K., Schwandt, C., See, T., Snead, C., I, F.S., Stephan, T., Stroud, R., Teslich, N., Trigo- Rodríguez, J., Tuzzolino, A., Troadec, D., Tsou, P., Warren, J., Westphal, A., Wozniakiewicz, P., Wright, I., Zinner, E., 2006. Impact features on Stardust: implications for comet 81P/Wild 2. Dust Sci 314, 1716-1719.

Hynek, B.M., Osterloo, M.K., Kierein-Young, K.S., 2015. Late-stage formation of Martian chloride salts through ponding and evaporation. Geology 43 (9), 787-790.

Ishii, H.A., Bradley, J.P., Dai, Z.R., Chi, M., Kearsley, A.T., Burchell, M.J., Browning, N.D., Molster, F., 2008. Comparison of Comet 81P/Wild 2 Dust with interplanetary dust from comets. Science 319 (5862), 447-450.

Jerolmack, D.J., 2013. Pebbles on Mars. Science 340, 1055-1056.

Jorn, L.V.H., Moroz, A., Maturilli, Bischoff, A., Warell, J., Sprague, A., Palomba, E., 2007. A set of laboratory analogue materials for the MERTIS instrument on the ESA BepiColombo mission to Mercury. Adv. Space Res. 40 (2), 272-279.

Just, G.H., Joy, K.H., Roy, M.J., Smith, K.L., 2020. Geotechnical characterisation of two new low-fidelity lunar regolith analogues (UoM-B and UoM-W) for use in large-scale engineering experiments. Acta Astronaut. 173, 414-424.

Kapui, Z., Kereszturi, A., Kiss, K., Szalai, Z., Yuenjvari, G.U., Hickman-Lewis, K., Foucher, F., Westall, F., 2018. Fluvial or aeolian grains? Separation of transport agents on Mars using earth analogue observations. Planet. Space Sci. 163, 56-76.

Kearsley, A.T., Burchell, M.J., Horz, F., Cole, M.J., Schwandt, C.S., 2006. Laboratory simulation of impacts on aluminum foils of the Stardust spacecraft: calibration of dust particle size from comet Wild-2. Meteoritics Planet Sci. 41, 167-180.

Kearsley, A.T., Burchell, M.J., Price, M.C., Graham, G.A., Wozniakiewicz, P.J., Cole, M.J., Foster, N.J., Teslich, N., 2009. Interpretation of Wild 2 dust fine structure: comparison of Stardust aluminum foil craters to the three-dimensional shape of experimental impacts by artificial aggregate particles and meteorite powders. Meteoritics Planet Sci. 44, 1489-1509.

Kelley, D.S., 2005. From the mantle to microbes the Lost city hydrothermal field. Oceanography 18 (3), 32-45.

Klein, H., Lederberg, J., Rich, A., Horowitz, N.H., Oyama, V.I., Levin, V., 1976. The Viking mission search for life on Mars. Nature 262, 24-27.

Kompanichenko, V.N., 2019. Exploring the Kamchatka geothermal region in the context of life's beginning. Life 9 (2), 41.

Kulp, T.R., 2014. Arsenic and primordial life. Nat. Geosci. 7, 785-786. 
Lambert, P., Lebreton, J.-P., Cirir consortium, 2019. The Rochechouart impact geosite for research, education and training. EPSC-DPS Joint Meeting 2019. EPSC Abstracts 13, EPSC-DPS2019-1934-3.

Lebreton, J.-P., Witasse, O., Sollazzo, C., Blancquaert, T., Couzin, P., Schipper, A.-M., Jones, J.B., Matson, D.L., Gurvits, L.I., Atkinson, D.H., Kazeminejad, B., Perez- Ayúcar, M., 2005. An overview of the descent and landing of the Huygens probe on Titan. Nature 438, 758-764.

Leveille, R., 2009. Validation of astrobiology technologies and instrument operations in terrestrial analogue environments. C. R. Palevol 8, 637-648.

Levin, G.V., Straat, P.A., 2016. The case for extant life on Mars and its possible detection by the viking labeled release experiment. Astrobiology 16, 798-810.

Le Roy, L., Briani, G., Briois, C., Cottin, H., Fray, N., Thirkell, L., Poulet, G., Hilchenbach, M., 2012. On the prospective detection of polyoxymethylene in comet 67P/Churyumov-Gerasimenko with the COSIMA instrument on board Rosetta. Planet. Space Sci. 65, 83-92.

Lofgren, G.E., Horz, F., Eppler, D., 2011. Geologic field training of the Apollo astronauts and implications for future manned exploration. In: Analogs for Planetary Exploration, vol. 483. The Geological Society of America, Special Paper, pp. 33-48.

Mangold, N., Baratoux, D., Arnalds, O., Bardintzeff, J.-M., Platevoet, B., Gregoire, M., Pinet, P., 2011. Segregation of olivine grains in volcanic sands in Iceland and implications for Mars. Earth Planet Sci. Lett. 310, 233-243.

Mangold, N., Carter, J., Poulet, F., Dehouck, E., Ansan, V., Loizeau, D., 2012. Late hesperian aqueous alteration at majuro crater, Mars. Planet. Space Sci. 72, 18-30.

Mangold, N., Schmidt, M., Fisk, M., d null, O.F., McLennan, S., Ming, D., Sautter, V., Sumner, D., Williams, A., Clegg, S., Cousin, A., Gasnault, O., Gellert, R., Grotzinger, J., Wiens, R., 2017. Classification scheme for sedimentary and igneous rocks in Gale crater, Mars. Icarus 284, 1-17.

Manzari, P., Angelis, S.D., Sanctis, M.C.D., Iorio, T.D., Ammannito, E., Bost, N., Foucher, F., Westall, F., 2016. Microimaging VIS-IR spectroscopy of ancient volcanic rocks as Mars analogues. Earth Space Sci 3, 14.

Marlow, J.J., Martins, Z., Sephton, M.A., 2008. Mars on Earth: soil analogues for future Mars missions. Astron. Geophys. 49, 20-23.

Martins, Z., Cottin, H., Kotler, J.M., Carrasco, N., Cockell, C.S., de la Torre Noetzel, R., Demets, R., de Vera, J.-P., d'Hendecourt, L., Ehrenfreund, P., Elsaesser, A., Foing, B., Onofri, S., Quinn, R., Rabbow, E., Rettberg, P., Ricco, A.J., Slenzka, K., Stalport, F., ten Kate, I.L., van Loon, J.J.W.A., Westall, F., 2017. Earth as a tool for astrobiology-A European perspective. Space Sci. Rev. 209, 43-81.

Matthewman, R., Court, R.W., Crawford, I.A., Jones, A.P., Joy, K.H., Sephton, M.A., 2015. The Moon as a recorder of organic evolution in the early solar system: a lunar regolith analogue study. Astrobiology 15 (2), 154-168.

Matthewman, R., Crawford, I.A., Jones, A.P., Joy, K.H., Sephton, M.A., 2016. Organic matter responses to radiation under lunar conditions. Astrobiology 16 (11), 900-912.

Maturilli, A., Helbert, J., Ferrari, S., Davidsson, B., D’Amore, M., 2016. Characterization of asteroid analogues by means of emission and reflectance spectroscopy in the 1- to 100- $\mu \mathrm{m}$ spectral range. Earth Planets Space 68 (1), 113.

McSween, H.Y., Taylor, G.J., Wyatt, M.B., 2009. Elemental composition of the martian crust. Science 324, 736-739.

Meinert, C., Filippi, J.-J., Marcellus, P.D., d'Hendecourt, L., Meierhenrich, U.J., 2012. N-(2-Aminoethyl)glycine and amino acids from interstellar ice analogues. ChemPlusChem 77, 186-191.

Meinert, C., Myrgorodska, I., de Marcellus, P., Buhse, T., Nahon, L., Hoffmann, S.V., d'Hendecourt, L., Meierhenrich, U.J., 2016. Ribose and related sugars from ultraviolet irradiation of interstellar ice analogs. Science 352, $208-212$.

Melosh, H.J., Collins, G.S., 2005. Meteor Crater formed by low-velocity impact. Nature 434, 157.

MEPAG, 2012. Planning for Mars returned sample science: final report of the MSR end-toend international science analysis group (E2E-iSAG). Astrobiology 12 (3), 175-230.

Morgan, J.W., Ganapathy, R., Higuchi, H., Urs, K., 1976. Volatile and siderophile trace elements in anorthositic rocks from Fiskenaesset. West Greenland: comparison with lunar and meteoritic analogues. Geochem. Cosmochim. Acta 40 (8), 861-887.

Nakamura, T., Matsuoka, M., Amano, K., Kobayashi, S., Mita, H., Brunetto, R., Lantz, C., Hiroi, T., Zolensky, M., Kitazato, K., Sugita, S., Honda, R., Morota, T., Tatsumi, E., Milliken, R., Iwata, T., Kameda, S., Sawada, H., Abe, M., Ohtake, M., Matsuura, S., Arai, T., Nakauchi, Y., Mogi, K., Yamashita, S., Sato, Y., Ka, H., Honda, C., Yokota, Y., Yamada, M., Kouyama, T., Sakatani, N., Senshu, H., Hirata, N., Suzuki, H., Yoshioka, K., Hayakawa, M., Cho, Y., Pilorget, C., Poulet, F., Riu, L., Bibring, J.-P., Takir, D., Domingue, D., Vilas, F., Barucci, M., Perna, D., Palomba, E., Galiano, A., Tsumura, K., Osawa, T., Komatsu, M., Nakato, A., 
Arai, T., Takato, N., Matsunaga, T., Yamaguchi, A., Imae, N., Kojima, H., Nakazawa, S., Tanaka, S., Yoshikawa, M., Watanabe, S., Tsuda, Y., 2019a. Possible interpretations of visible/near-infrared spectra of asteroid Ryugu obtained by the Hayabusa2 mission. 50th Lunar and Planetary Science Conference. LPI Contrib. 2132 abstract 1681.

Nakamura, T., Lantz, C., Kobayashi, S., Nakauchi, Y., Amano, K., Brurnetto, R., Matsumoto, M., Matsuoka, M., Noguchi, T., Matsumoto, T., Miyake, A., Tsuchiyama, A., Zolensky, M., 2019b. Experimental reproduction of space weathering of C-type asteroids by He exposure to shocked and partially dehydrated carbonaceous chondrites. 82nd Annual Meeting of the Meteoritical Society, LPI Contrib. 2157 abstract 6211.

Ono, F., Minami, K., Saigusa, M., Matsushima, Y., Mori, Y., Takarabe, K., Saini, N., Yamashita, M., 2010. Life of Artemia under very high pressure. J. Phys. Chem. Solid. 71, 1127-1130.

Orange, F., Westall, F., Disnar, J.R., Prieur, D., Bienvenu, N., Leromancer, M., Defarge, C., 2009. Experimental silicification of the extremophilic Archaea Pyrococcus abyssi and Methanocaldococcus jannaschii: applications in the search for evidence of life in early Earth and extraterrestrial rocks. Geobiology 7, 403-418.

Osinski, G.R., Battler, M., Caudill, C.M., Francis, R., Haltigin, T., Hipkin, V.J., Kerrigan, M., Pilles, E.A., Pontefract, A., Tornabene, L.L., Allard, P., Bakambu, J.N., Balachandran, K., Beaty, D.W., Bednar, D., Bina, A., Bourassa, M., Cao, F., Christoffersen, P., Choe, B.-H., Cloutis, E., Cote, K., Cross, M., D’Aoust, B., Draz, O., Dudley, B., Duff, S., Dzamba, T., Fulford, P., Godin, E., Goordial, J., Galofre, A.G., Haid, T., Harrington, E., Harrison, T., Hawkswell, J., Hickson, D., Hill, P., Innis, L., King, D., Kissi, J., Laughton, J., Li, Y., Lymer, E., Maggiori, C., Maloney, M., Marion, C.L., Maris, J., Mcfadden, S., McLennan, S.M., Mittelholz, A., Morse, Z., Newman, J., O'Callaghan, J., Pascual, A., Patel, P., Picard, M., Pritchard, I., Poitras, J.T., Ryan, C., Sapers, H., Silber, E.A., Simpson, S., Sopoco, R., Svensson, M., Tolometti, G., Uribe, D., Wilks, R., Williford, K.H., Xie, T., Zylberman, W., 2019. The CanMars Mars sample return analogue mission. Planet. Space Sci. 166, 110-130.

Panieri, G., Lugli, S., Manzi, V., Roveri, M., Schreiber, B.C., Palinska, K.A., 2010. Ribosomal RNA gene fragments from fossilized cyanobacteria identified in primary gypsum from the late Miocene. Italy. Geobiology 8 (101), 11.

Pernet-Fisher, J.F., Joy, K.H., Martin, D.J.P., Donaldson Hanna, K.L., 2017. Assessing the shock state of the lunar highlands: implications for the petrogenesis and chronology of crustal anorthosites. Sci. Rep. 7 (1), 1-12.

Phinney, R.A., O’keefe, J.A., Adams, J.B., Gault, D.E., Masursky, H., Kuiper, G.P., Collins, R.J., Shoemakser, E.M., 1969. Implications of the surveyor 7 results. J. Geophys. Res. 74, 6053-6080.

Pondrelli, M., Rossi, A.P., Le Deit, L., Fueten, F., van Gasselt, S., Glamoclija, M., Cavalazzi, B., Hauber, E., Franchi, F., Pozzobon, R., 2015. Equatorial layered deposits in Arabia Terra, Mars: facies and process variability. Geol. Soc. Am. Bull. 127, 1064-1089.

Preston, L., Grady, M., Barber, S., 2012. CAFE - Concepts for Activities in the Field for Exploration, TN2: the Catalogue of Planetary Analogues. The Open University. 98.

Preston, L.J., Dartnell, L.R., 2014. Planetary habitability: lessons learned from terrestrial analogues. Int. J. Coal Geol. 13, 81-

Ramkissoon, N.K., Pearson, V.K., Schwenzer, S.P., Schroder, C., Kirnbauer, T., Wood, D., Seidel, R.G.W., Miller, M.A., Olsson-Francis, K., 2019. New simulants for martian regolith: controlling iron variability. Planet. Space Sci. 179, 104722.

Rampelotto, P.H., 2010. Resistance of microorganisms to extreme environmental conditions and its contribution to astrobiology. Sustainability 2, 1602-1623.

Reiss, D., Hauber, E., Hiesinger, H., Jaumann, R., Trauthan, F., Preusker, F., Zanetti, M., Ulrich, M., Johnsson, A., Olvmo, M., Carlsson, E., Johansson, H.A.B., McDaniel, S., 2011. Terrestrial gullies and debris-flow tracks on Svalbard as planetary analogs for Mars. In: Analogs for Planetary Exploration, vol. 483. The Geological Society of America, Special Paper, pp. 165175.

Ruff, S.W., Farmer, J.D., 2016. Silica deposits on Mars with features resembling hot spring biosignatures at El Tatio in Chile. Nat. Commun. 7, 13554.

Rumpf, M.E., Needham, H., Fagents, S.A., 2020. Thicknesses of lava flows in satellite images: comparison of layered mare units with terrestrial analogs. Icarus 350, 113853.

Russell, S., Smith, C., Hutzler, A., Meneghin, A., Berthoud, L., Aleon, J., Bennett, A., Bridges, J., Brucato, J.R., Debaille, V., Dryer, B., Ferriere, L., Folco, L., Foucher, F., Franchi, I., Gemelli, M., Gounelle, M., Grady, M., Guest, M., Holt, J., Leuko, S., Longobardo, A., Marrocchi, Y., Palomba, E., Pottage, T., Rettberg, P., Rotundi, A., Vrublevskis, J., Westall, F., Zipfel, J., 2019. EURO-CARES - A European Sample Curation Facility for Sample Return Missions, 2019 IEEE Aerospace Conference. Big Sky, MT, USA, pp. 1-9.

Salpas, P.A., Haskin, L.A., McCallum, I.S., 1983. Stillwater anorthosites: a lunar analog? J. Geophys. Res. 88, B27-B39. Supplement. 
Schultz, P., Harris, R.S., Clemett, S., Thomas-Keprta, K., Zarate, M., 2014. Preserved flora and organics in impact melt breccias. Geology 42, 515-518.

Schulz, R., Benkhoff, J., 2006. BepiColombo: payload and mission updates. Adv. Space Res. 38 (4), 572-577.

Shtarkman, Y.M., Koçer, Z.A., Edgar, R., Veerapaneni, R.S., D’Elia, T., Morris, P.F., Rogers, S.O., 2013. subglacial lake Vostok (Antarctica) accretion ice contains a diverse set of sequences from aquatic, marine and sediment-inhabiting bacteria and eukarya. PloS One 8, 13.

Smith, C.L., Russell, S.S., Hutzler, A., Meneghin, A., Brucato, J., Rettberg, P., Leuko, S., Longobardo, A., Palomba, E., Rotundi, A., Ferriere, L., Bennett, A., Pottage, T., Folco, L., Debaille, V., Aleon, J., Gounelle, M., Marrochi, Y., Franchi, I.A., Westall, F., Zipfel, J., Foucher, F., Berthoud, L., Vrublevskis, J., Bridges, J.C., Holt, J., Guest, M., Matussi, S., Grady, M.M., 2021. A roadmap for a European extraterrestrial sample curation facility - the EURO-CARES project. In: Longobardo, Andrea (Ed.), Sample Return Missions. Elsevier. In press.

Surkov, Y.A., Barsukov, V.L., Moskalyeva, L.P., Kharyukova, V.P., Kemurdzhian, A.L., 1984. New data on the composition, structure, and properties of Venus rock obtained by Venera 13 and Venera 14. J. Geophys. Res. 89, B393-B402. Supplement.

Taylor, L.A., Pieters, C.M., Britt, D., 2016. Evaluations of lunar regolith simulants. Planet. Space Sci. 126, 1-7.

Tosca, N.J., McLennan, S.M., Lindsley, D.H., Schoonen, M.A.A., 2004. Acid-sulfate weathering of synthetic Martian basalt: the acid fog model revisited. J. Geophys. Res. 109, E05003.

Ushakov, I.B., Morukov, B.V., Bubeev, Y.A., Gushin, V.I., Vasil'eva, G.Y., Vinokhodova, A.G., Shved, D.M., 2014. Main findings of psychophysiological studies in the Mars 500 experiment. Herald Russ. Acad. Sci. 84 (2), 212-221.

Vago, J.L., Westall, F., Coates, A.J., Jaumann, R., Korablev, O., Ciarletti, V., Mitrofanov, I., Josset, J.-L., De Sanctis, M.C., Bibring, J.-P., Rull, F., Goesmann, F., Steininger, H., Goetz, W., Brinckerhoff, W., Szopa, C., Raulin, F., Westall, F., Howell, G., Edwards, M., Whyte, L.G., Fairen, A.G., Bibring, J.-P., Bridges, J., Hauber, E., Ori, G.G., Werner, S., Loizeau, D., Kuzmin, R.O., Williams, .M.E., Flahaut, J., Forget, F., Vago, J.L., Rodionov, D., Korablev, O., Svedhem, H., Sefton-Nash, E., Kminek, E., Lorenzoni, L., Joudrier, L., Mikhailov, V., Zashchirinskiy, A., Alexashkin, S., Calantropio, F., Merlo, A., Poulakis, P., Witasse, O., Bayle, O., Bayon, S., Meierhenrich, U., Carter, J., García-Ruiz, J.M., Baglioni, P., Haldemann, A., Ball, A.J., Debus, A., Lindner, A., Haessig, F., Monteiro, D., Trautner, R., Voland, C., Rebeyre, P., Goulty, D., Didot, F., Durrant, S., Zekri, E., Koschny, D., Toni, A., Visentin, G., Zwick, M., van Winnendael, M., Azkarate, M., Carreau, C., the ExoMars Project Team, 2017. Habitability on early Mars and the search for biosignatures with the ExoMars rover. Astrobiology 17 (6-7), 471-510.

Vandenabeele, P., Jehlicka, J., Vitek, P., Edwards, H.G.M., 2012. On the definition of Raman spectroscopic detection limits for the analysis of biomarkers in solid matrices. Planet. Space Sci. 62, 48-54.

Vitek, P., Osterrothova, K., Jehlicka, J., 2009. Beta-carotene-A possible biomarker in the Martian evaporitic environment: Raman micro-spectroscopic study. Planet. Space Sci. 57, 454-459.

von Ehrenfried, M., 2019. From Cave Man to Cave Martian, Living in Caves on the Earth, Moon and Mars. Springer, Praxis Publishing, Chichester, UK.

Weider, S.Z., Swinyard, B.M., Kellett, B.J., Howe, C.J., Joy, K.H., Crawford, I.A., Gow, J., Smith, D.R., 2011. Planetary X-ray fluorescence analogue laboratory experiments and an elemental abundance algorithm for C1XS. Planet. Space Sci. 59 (13), $1393-1407$.

Wentworth, S.J., Gibson, E.K., Velbel, M.A., McKay, D.S., 2005. Antarctic dry valleys and indigenous weathering in Mars meteorites: implications for water and life on Mars. Icarus 174 (2), 383-395.

Westall, F., 2008. Morphological biosignatures in early terrestrial and extraterrestrial materials. Space Sci. Rev. 135, 95-114.

Westall, F., Foucher, F., Cavalazzi, B., de Vries, S.T., Nijman, W., Pearson, V., Watson, J., Verchovsky, A., Wright, I., Rouzaud, J.N., Marchesini, D., Anne, S., 2011.Volcaniclastic habitats for early life on Earth and Mars: a case study from $~ 3.5$ Gaold rocks from the Pilbara, Australia. Planet. Space Sci. 59, 1093-1106.

Westall, F., Foucher, F., Bost, N., Bertrand, M., Loizeau, D., Vago, J.L., Kminek, G., Gaboyer, F., Campbell, K.A., Breheret, J.G., Gautret, P., Cockell, C.S., 2015.Biosignatures on Mars: what, where, and how? Implications for the search for martian life. Astrobiology 15 (11), 998-1029.

Wozniakiewicz, P.J., Kearsley, A.T., Burchell, M.J., Foster, N.J., Cole, M.J., Bland, P.A., Russel, S.S., 2009. In situ analysis of residues resulting from laboratory impacts into aluminun 1100 foil: implications for Stardust crater analyses. Meteoritics Planet Sci. 44, 1541-1559.

Wozniakiewicz, P.J., Kearsley, A.T., Ishii, H.A., Burchell, M.J., Bradley, J.P., Teslich, N., Cole, M.J., Price, M.C., 2012. The origin of crystalline residues in Stardust Al foils: surviving cometary dust or crystallized impact melts? Meteoritics Planet Sci. 47 , 660-670. 